REVIEW ARTICLE

\title{
Designing vegetation barriers for urban air pollution abatement: a practical review for appropriate plant species selection
}

\author{
Yendle Barwise $\mathbb{D}^{1}$ and Prashant Kumar $\mathbb{D}^{1 凶}$
}

Vegetation can form a barrier between traffic emissions and adjacent areas, but the optimal configuration and plant composition of such green infrastructure $(\mathrm{Gl})$ are currently unclear. We examined the literature on aspects of $\mathrm{Gl}$ that influence ambient air quality, with a particular focus on vegetation barriers in open-road environments. Findings were critically evaluated in order to identify principles for effective barrier design, and recommendations regarding plant selection were established with reference to relevant spatial scales. As an initial investigation into viable species for UK urban Gl, we compiled data on 12 influential traits for 61 tree species, and created a supplementary plant selection framework. We found that if the scale of the intervention, the context and conditions of the site and the target air pollutant type are appreciated, the selection of plants that exhibit certain biophysical traits can enhance air pollution mitigation. For super-micrometre particles, advantageous leaf micromorphological traits include the presence of trichomes and ridges or grooves. Stomatal characteristics are more significant for sub-micrometre particle and gaseous pollutant uptake, although we found a comparative dearth of studies into such pollutants. Generally advantageous macromorphological traits include small leaf size and high leaf complexity, but optimal vegetation height, form and density depend on planting configuration with respect to the immediate physical environment. Biogenic volatile organic compound and pollen emissions can be minimised by appropriate species selection, although their significance varies with scale and context. While this review assembled evidence-based recommendations for practitioners, several important areas for future research were identified.

npj Climate and Atmospheric Science (2020)3:12; https://doi.org/10.1038/s41612-020-0115-3

\section{INTRODUCTION}

Air pollution is a momentous global issue, the greatest environmental hazard to human health, and responsible for approximately one in every nine deaths each year ${ }^{1}$. It is of particular concern in urban areas, where elevated pollutant concentrations and potential sufferers converge ${ }^{2-4}$. This is intensified by projected global population growth ${ }^{5}$, increased urbanisation ${ }^{1}$ and impacts of climate change on atmospheric conditions and weather variability ${ }^{6}$.

Beyond the myriad policy, technological and cultural changes required for the curtailment of emissions at the source, the mitigation of ongoing ambient air pollution is essential in order to reduce human exposure ${ }^{7}$. Appropriate green infrastructure $(\mathrm{Gl})$ is broadly recognised as one of several promising passive control systems for air pollution, and the literature detailing the positive effects that plants and vegetation may have on air quality is substantial (Table 1). Gallagher et al. ${ }^{8}$ highlight the concomitant benefits of employing porous (green) as opposed to solid barriers (including walls and parked cars) to mitigate air pollution where possible. Numerous studies involving Gl corroborate its costeffective multifunctionality by virtue of the variety of ecosystem services that may be achieved or enhanced, including ambient cooling and microclimate regulation (which bears additional gains in reducing local energy consumption and related emissions) $)^{9,10}$, storm water attenuation ${ }^{9}$, improved mental and physical health ${ }^{11-}$ 15 , biodiversity support ${ }^{9}$, and climate change mitigation and adaptation ${ }^{16-18}$. This latter aspect is particularly significant with regards to air quality. In an article on the intricate, intertwined relationship between air pollution and climate change, Tibbetts $^{6}$ suggests that combating one often supports abatement of the other.

There are contrasting definitions of $\mathrm{Gl}$ both between and within research disciplines ${ }^{19}$. This review concerns the use of trees and shrubs to form barriers between road traffic emissions and pedestrians. The terms ' $\mathrm{Gl}$ ' and 'vegetation barrier' are henceforth used interchangeably unless otherwise indicated. Similarly, for expediency, the term 'species' is used to distinguish between individual plants for selection, with recognition that the plant may be more properly described as, for example, a cultivar.

Transport emissions constitute a dominant source of urban air pollution ${ }^{20-23}$, and are characterised by a range of noxious gaseous pollutants, such as carbon monoxide (CO) and nitrogen oxides $\left(\mathrm{NO}_{\mathrm{x}}\right)$, and particulate matter (PM), including black carbon $(\mathrm{BC})^{21,23,24}$. Beyond vehicle exhaust emissions, non-exhaust but traffic-related emissions (e.g. brake wear) are considered to be significant sources of PM, which is then re-suspended by trafficrelated turbulence ${ }^{25,26}$. In an examination of air pollutant trends in London between 2005-2009 and 2010-2014, Font and Fuller ${ }^{27}$ found that abatement measures in some locations were offset by changes in traffic flow; that is, that increased non-exhaust sources of coarse PM, including road wear by heavier vehicles, offset reductions in exhaust emissions. This has implications for the assumed benefit of a move towards the use of electric vehicles for ambient air quality ${ }^{28}$. Similarly, for ultrafine particles (UFPs), the relative contribution from non-exhaust sources is projected to rise as cleaner fuels are adopted ${ }^{26}$. For both fine and coarse PM, realtime respiratory deposition doses are higher for pedestrians than 
Table 1. Summary of perspectives, review articles and reports on Gl design and/or interactions with air pollution.

Authors, ref. Description

Eisenman et al. ${ }^{153}$

An interdisciplinary review on urban trees, air pollution and asthma. Found no scientific consensus that urban trees reduce asthma, and that different disciplines follow divergent approaches to the research topic. Recommended that future research on urban Gl and ecosystem services should involve interdisciplinary collaboration due to the complex relationship between significant factors

Ferranti et al. ${ }^{47}$

An overview report on interactions between urban GI and air quality, providing succinct guidance for built environment practitioners. Itemised sources and health impacts of key pollutants, as well as the influences of urban form on the relationship between $\mathrm{Gl}$ and air quality

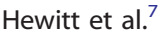

A perspective on the context-dependency of GI implementation for improved urban air quality. Provided a conceptual framework to support decision making for the appropriate positioning of $\mathrm{Gl}$ and selection of $\mathrm{Gl}$ type (e.g. green wall, hedge, etc.). Also presented six policy interventions that research suggests will lead to improved air quality

Tiwari et al. ${ }^{48}$

A review paper on the treatment of Gl by dispersion models at the microscale $(10-500 \mathrm{~m})$ and macroscale $(5-100 \mathrm{~km})$, including the parameterisation of deposition velocities and datasets for particulate and gaseous pollutant deposition schemes. Found that $\mathrm{Gl}$ can reduce human exposure at the microscale via deposition and pollutant redistribution, and enhance pollutant removal at the macroscale via deposition and increased atmospheric turbulence

Air Quality Expert Group ${ }^{42}$ A report on the influences of vegetation on urban air pollution, with an additional focus on policy implications. Discussed influences on dispersion and deposition of air pollutants as separate sections. Concluded that trees and vegetation are generally beneficial at local scale but are not a solution at city scale

Buccolieri et al. ${ }^{87}$

A review paper on the modelling of urban trees in CFD simulations, with a focus on aerodynamic, deposition and resuspension effects, as well as thermal effects. Conclusions included that the influence of street trees on pollutant dispersion is much more significant than on deposition, but that pollutant concentrations at local scale depend on the complex inter-relationship of vegetation design characteristics, pollutant type and emission rates, meteorological conditions and the surrounding physical environment

Gourdji ${ }^{132}$

A review paper on different green roof types and plants for green roofs regarding air pollution mitigation, with an explicit focus on particulate matter, ozone and nitrogen dioxide. Provided recommendations for green roof type and potentially effective plants for the plant hardiness zone 5 of Montreal, Quebec

Hirons and Sjöman ${ }^{41}$

A decision-support tool for the selection of viable species under several UK urban environmental conditions, based upon relevant research to date and observations in the field

Mori et al. ${ }^{154}$

A review paper on the effects of air pollution on human health, sources of air pollution and aspects of urban Gl that may positively influence air pollutant interception. Did not include species-specific information, apart from on isoprene emissions. Found that total leaf area is significant and that the immediate environment influences the impact of $\mathrm{Gl}$ form

Abhijith et al. ${ }^{20}$

A review paper on the effects of various forms of $\mathrm{Gl}$ (trees, hedges, green walls and green roofs) on ambient air quality in open road and street canyon conditions. Summarised positive and negative aspects of each form under each condition. Found that $\mathrm{Gl}$ can mitigate air pollution if designed according to context

Baldauf $^{34}$

A review paper on design considerations for roadside vegetation, with a focus on open-road conditions. Summarised physical (e.g. dimensional) and vegetation characteristics (non-species-specific) that are either beneficial or detrimental to downwind ambient air quality. Provided generic recommendations for vegetation barrier design

Willis and Petrokofsky ${ }^{18} \quad$ A review paper on the natural capital, advantages and detrimental aspects of urban trees. Provided an overview of significant underlying processes and interactions between urban trees and human health and wellbeing, including the importance of careful species selection with regards to air quality

Grote et al. ${ }^{77}$

A review paper on vegetation traits that affect urban air quality, with reference to common European trees. Found that: the most important traits are canopy density, foliage longevity, water-use strategy, and bVOC emissions; knowledge gaps around pollen and bVOC emissions exist; the influence of each vegetation trait on ecosystem services other than air pollution mitigation should also be considered

Salmond et al..$^{50}$

A review paper on ecosystem services and disservices (including climate and air quality regulation, as well as cultural services) provided by urban trees. Found that the majority of attempts to evaluate the impacts of Gl have followed regional-scale, reductionist approaches, and concluded that species selection and planting configuration should be informed by a holistic process that considers synergies and trade-offs at appropriate scales for specific objectives

Gallagher et al. $^{8}$

A review paper on porous (vegetation) and solid barriers as passive control systems for urban air pollution. Significant points include: passive barriers can abate air pollutants and present additional benefits, including noise pollution reduction; representations of dispersion in experimental and modelling studies are incomprehensive; engaging urban planners in dialogue and developing appropriate design guidelines are important next steps

Janhäll ${ }^{29}$

A review paper on the influences of urban vegetation characteristics on ambient air pollution, with a focus on particulate pollutants. Found that: appropriate design and vegetation selection is critical to successful pollution mitigation; dispersion and deposition should both be considered; high-level vegetation should be limited where it may obstruct clean air from above; vegetation should be placed proximate to the source; barrier porosity is a key factor for pollutant filtration

Mullaney et al. ${ }^{124}$

A review paper on the advantages and obstacles to growing trees in paved streets. Summarised the benefits provided by urban trees, the stresses imposed on vegetation by typical urban environments, the costs of pavement damage by tree roots, and methods of preventing pavement damage and supporting urban tree health

Calfapietra et al. ${ }^{155}$

A review paper on the role of bVOC emissions from urban trees in ozone formation and concentrations. Found a dearth of studies on the influences of bVOCs on air quality in urban areas, and that the impacts of air pollution on the biochemical reactions and physiological responses of vegetation that lead to bVOC emissions remain undetermined. Highlighted the need for further research into the cost-benefit balance of bVOC emissions as precursors of $\mathrm{O}_{3}$ and as a mechanism by which plants are able to tolerate stressful conditions 


\begin{tabular}{|ll|}
\hline Table 1 continued & Description \\
\hline Authors, ref. & $\begin{array}{l}\text { A review paper on the positive and negative aspects of urban vegetation for air quality. Found that: urban tree planting } \\
\text { can improve air quality and mitigate some of the effects of climate change; careful design of Gl interventions should be } \\
\text { undertaken before implementation on the ground; indiscriminate planting can result in unintended consequences, } \\
\text { including exacerbated air pollution }\end{array}$ \\
\hline Gl green infrastructure, bVOC biogenic volatile organic compound. \\
\hline
\end{tabular}

for those travelling by public transport or by $\mathrm{car}^{23}$. To minimise pedestrian exposure, the placement of abatement measures as near as practicable to traffic-related PM sources (i.e. proximate to the road) is recommended ${ }^{7,20,29-31}$, particularly for UFP deposition ${ }^{28}$.

Vegetation can be utilised to form such a roadside barrier, limiting the exposure of pedestrians to air pollution $8,20,32-35$. The optimum physical structure of a vegetation barrier is contextdependent and should take into account the topography of each built environment ${ }^{7,20}$. Generic barrier shape recommendations have been provided for two typical urban environments: (i) open road and (ii) built-up street canyon ${ }^{20,31}$. However, these recommendations do not account for the influence of specific plant choice, which is, therefore, a central aspect of this review.

A number of studies highlight that the interactions between individual plants and ambient air quality are complex and that species can have both positive and negative effects ${ }^{18,36-38}$. Willis and Petrokofsky ${ }^{18}$ indicate that an understanding of the positive and negative aspects of each considered species is crucial to successful Gl design. Generic recommendations regarding species choice for air pollution abatement are provided by several sources $37,39,40$. However, these recommendations do not account for the suitability of each plant's expected morphology to the appropriate barrier shape with respect to its surrounding built environment.

A vast amount of data on the morphology of individual tree species is available. For example, Hirons and Sjöman ${ }^{41}$ presented a tree selection guide that includes species-specific information on expected morphology, drawing upon findings from relevant research to date as well as practitioner experience. This guide also includes some information on the observed environmental tolerance (e.g. regarding drought) exhibited by each species. However, this work does not include cost-benefit information regarding the potential effects of each particular species on ambient air quality, nor under contrasting urban conditions at a local scale (i.e. street canyon or open-road environments). Indeed, there is an apparent lack of published sources that provide holistic guidance for practitioners and planners on species selection and vegetation barrier design for improved air quality (Table 1). Such consolidated information is imperative for the successful implementation of research outputs in practice ${ }^{7}$. To fill this gap, this review synthesises the literature to indicate recommended design and management approaches for vegetation barriers under context-specific circumstances. In doing so, it forms a vital step towards creating a complete Gl implementation framework and provides a template upon which ongoing research may build, for the benefit of optimised air pollution mitigation by Gl. The novelty of this review lies in its holistic approach and the robust and practical recommendations achieved thereof, with reference not only to plant and leaf traits that influence air quality but also to significant considerations regarding barrier configuration and management for sustainable air pollution abatement at roadsides.

We identified relevant research papers and review articles in Web of Science, ProQuest and Scopus, using combinations of keywords, including 'plant', 'species', 'air pollution', 'air quality', 'green infrastructure' and 'vegetation', with no restrictions on the year of publication. The search results were then refined and selected for inclusion in this review if they were written in English and concerned interactions between ambient air pollution or air quality and $\mathrm{Gl}$, vegetation or individual plants, with a particular focus on species-specific studies undertaken in urban environments. Interactions between air quality, vegetation and climate change were considered to be beyond the scope of this review. Finally, this list was supplemented with a number of relevant papers and reports that were already known to us.

This review extends beyond the scope of recent studies regarding air pollution abatement by GI (Table 1), providing a synthesis of findings on three essential points for effective vegetation barrier design: (i) contextual barrier dimensions and configuration; (ii) disadvantageous and advantageous vegetation traits; and (iii) species-specific suitability under contrasting UK urban environments. This novel, three-pronged approach produced a wealth of data that was subsequently integrated and refined until a clear set of substantive findings were deduced to formulate context-specific design recommendations as an accessible, pragmatic framework. The formulation of this framework comprises an important, natural progression from several highly relevant studies (Table 1). Finally, knowledge gaps that have been addressed by this analysis of the literature are summarised, and important areas for future research are identified.

\section{INTERACTIONS BETWEEN GI AND AIR QUALITY AT DIFFERENT SPATIAL SCALES}

City scale

Vegetation is regarded as generally beneficial to air quality ${ }^{18,42,43}$. However, the relationship between vegetation and ambient air quality is complex. For descriptive purposes, the potentially beneficial influences of vegetation on air quality are broadly categorised under the processes of dry deposition and atmospheric dispersion $^{29,42}$. In line with complex system dynamics, the collective impacts of these processes are manifold and contextdependent, and related phenomena emerge at different scales $^{44,45}$

Dry deposition describes the process by which pollutants are at least temporarily removed from the ambient air by interception, sedimentation, capture, and other sub-processes (for PM) or by biochemical processes (for gaseous pollutants and UFPs). The influences of vegetation on this process are discussed later, under 'Advantageous aspects of Gl for air quality'. The capacity of vegetation for the direct removal of certain pollutants is considered to be negligible at city scale, with potential pollutant removal values of only a few percent under feasible greening scenarios $^{42}$. For example, vegetation is a poor sink for several gaseous pollutants, including nitrogen dioxide $\left(\mathrm{NO}_{2}\right)$, deposition of which is limited to stomatal uptake and therefore tends to occur during warmer months, when $\mathrm{NO}_{2}$ is less of a hazard ${ }^{42}$. Similarly, nitric acid (NO) is poorly mitigated by vegetation, partly due to significant NO emissions from vegetated soils when compared with bare soils ${ }^{42}$.

However, the spatial scale is key ${ }^{45}$; where the majority of urban infrastructure or surfaces are grey or impermeable at city scale, specific roadside locations (i.e. local-scale environments) offer ample opportunity for planting ${ }^{46}$, and the relative potential for 
pollution abatement at such sites may therefore be much higher ${ }^{47}$. Moreover, an important distinction exists between pollutant removal and exposure reduction, with the latter often achievable through local-scale manipulation of pollutant concentrations and air flows rather than extirpation of air pollution $^{7,20,36,42}$. For roadside environments, this requires a contextspecific account of the relationship between vegetation characteristics or form, street geometry, and meteorological conditions $^{45}$.

\section{Local scale}

At local scale, the potential for air pollution exposure reduction by appropriate $\mathrm{Gl}$ is well-supported (Table 1), particularly where $\mathrm{Gl}$ involves the physical separation of people from pollutant sources, such as by the use of vegetation barriers ${ }^{42,48}$. Indeed, numerous studies have found that vegetation can act as a physical barrier between air pollution and potential sufferers, effectively extending the distance between source and receptor $7,8,20,32,35$, although this function is not without provisos (see 'Trade-offs in plant selection'). Studies on the influences of such vegetation barriers on air quality have largely concerned atmospheric dispersion, and many have compared the dispersion effects of Gl with those of grey infrastructure or other non-porous barriers (Table 1). For example, Gallagher et al. ${ }^{8}$ reported that porous (vegetation) barriers can act as a passive method of air pollution amelioration by adjusting dispersion patterns in a similar manner to that which may be achieved by solid barriers.

Results from a recent study involving spatial analysis suggest that roadside $\mathrm{Gl}$ can be implemented with minimal necessary alterations to existing urban environments ${ }^{46}$. GI may therefore be utilised as one of many 'bridge' tools to mitigate exposure to air pollution while advancements in policy and technology work to reduce and resolve pollutant sources for the future ${ }^{7}$. The potential effectiveness of vegetation barriers to contribute towards such Gl is significant. Effective barrier design, however, entails alignment with contextual conditions.
Local-scale conditions determine optimal barrier dimensions and configuration. The optimal physical structure of a vegetation barrier is context-dependent, and should take into account the topography of each built environment in relation to local meteorological conditions ${ }^{20,49}$. This principle recognises that the effects of a vegetation barrier on pollutant dispersion, in particular, are determined by the barrier's interactions with airflow and turbulence ${ }^{42}$. The multifarious interactions between different forms of vegetation and wind conditions in relation to street geometry are discussed in several relevant reviews (Table 1), although research in this field is ongoing and the evidence base has grown over recent years (Supplementary Table S1).

Abhijith et al. $^{20}$ provide a comprehensive overview of the effects that different forms of vegetation can have on ambient air quality, depending upon the physical environment. The authors differentiate between two typical urban environments: (i) open road and (ii) built-up street canyon. In Table 2, we extrapolate recommendations from major findings by Abhijith et al. $^{20}$ with regards to the use of high-level (i.e. trees, with a canopy lifted from ground level) and low-level (i.e. shrubs and hedges, with leaf cover beginning at or near ground level) vegetation for air pollution abatement under each condition. The generic nature of these recommendations is necessitated by the key point that vegetation can both promote and disrupt pollutant dispersion, by exerting additional mechanical turbulence on the one hand and decreasing turbulent kinetic energy on the other ${ }^{20}$. Further research into this system is required in order to elucidate the influences of several related mechanisms, including feedback. For example, the fluidity of vegetation shape in relation to local meteorological conditions suggests that the effects of vegetation on dispersion are dynamic in situ ${ }^{42}$.

A distinction may also be drawn between high- and low-level vegetation in street canyons, with each bearing divergent influences upon dispersion according to aspect ratio and wind conditions (Table 2). In such environments, high-level vegetation can limit the exchange of air from above, trapping pollution at ground level ${ }^{29,50}$. Although increased deposition may offset

Table 2. Generic recommendations for the physical structure of vegetation in open-road and street canyon contexts, extrapolated from Abhijith et al. ${ }^{20}$.

Vegetation type Generic recommendations under each context

\begin{tabular}{cl} 
& Open road \\
\hline High-level vegetation $^{\text {b }}$ & Can improve pedestrian-side air quality when planted as a \\
barrier, although any effects are varied by wind conditions \\
(speed and direction), temperature, relative humidity and the \\
position and physical characteristics of the barrier; tall and \\
dense (low-porosity) vegetation is recommended; there should \\
be no gaps or breaks in the barrier; barrier thickness should \\
maximise available space, with an optimal thickness of $10 \mathrm{~m}$ or \\
more recommended; barrier length should extend beyond the \\
area of concern
\end{tabular}

Low-level vegetation ${ }^{c} \quad$ Many of the design recommendations for high-level vegetation in open-road conditions (above) apply equally to low-level vegetation; shrubs and hedges should form a contiguous barrier with trees, or be trained to a height of at least $2 \mathrm{~m}$ (above breathing height for pedestrians); barrier should be aligned parallel and proximate to the road, where low-level vegetation can mitigate pollutants at typical vehicle exhaust height
Street canyon $^{\mathrm{a}}$

Generally detrimental irrespective of configuration, although both the extent and form of influence on pollutant dispersion are determined by a combination of the aspect ratio (H/W) and local wind flow conditions; small and open-crowned trees, broadly spaced apart, may be implemented on the windward side of shallow canyons; where canyon trees already exist or must be replaced, stand density, crown size, crown density and tree height should all be kept to a minimum by thinning, pruning and the selection of smaller and lighter-crowned species

Not recommended in deep street canyons; can improve air quality along footpaths in shallow street canyons, but influence is not clear-cut; one central hedgerow is better than along each side of the street; hedgerow should extend through length of street canyon, without breaks; hedge/ shrub height and porosity are pivotal factors, with very lowlevel shrubs recommended for mid-depth canyons and dense vegetation with an optimal height of about $2 \mathrm{~m}$ recommended for shallow canyons

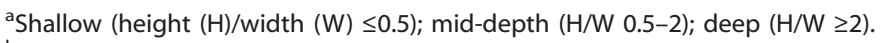

${ }^{\mathrm{b}}$ Trees, with a canopy lifted from the ground level.

'Shrubs and hedges, with leaf cover beginning at or near the ground level. 
some of the decreases in dispersion potentially caused by trees in street canyons ${ }^{51,52}$, it is generally suggested that only lowlevel vegetation (or, in deep street canyons, only green walls) be implemented, in order to facilitate both dispersion and deposition ${ }^{20}$.

In open-road environments, however, woody plants may be implemented to form a continuous barrier. Baldauf ${ }^{34}$ suggests that such barriers can improve pedestrian-side air quality, but due consideration must be given to critical parameters, including barrier height, thickness and porosity. For example, highly porous (lowdensity) vegetation barriers can reduce wind speed as it penetrates gaps, potentially resulting in pollutant accumulation downwind (i.e. within and beyond the barrier) ${ }^{34,53}$. Conversely, very low-porosity vegetation can limit pollution removal by restricting infiltration and forcing air pollutants to flow above and around the barrier or to recirculate and accumulate on the upwind or source side ${ }^{29,54}$. An optimal porosity may therefore be inferred to exist between both extremes.

Vegetation barrier design for air pollution abatement requires a mechanistic understanding of how barrier form affects the movement of air pollutants ${ }^{55}$. The provision of generic recommendations by Baldauf ${ }^{34}$ regarding barrier design supports the generalisation made by Abhijith et al. ${ }^{20}$ that the effects of vegetation in open-road environments are more reliable than those of street canyon environments, due in part to the influences of complex street canyon geometry on airflows. To establish optimal GI configuration in street canyons, pilot modelling studies should therefore be undertaken before implementation, wherever possible $e^{7,20}$

\section{TRADE-OFFS IN PLANT SELECTION}

The diverse influences of individual species on air quality are reflected by the immeasurable range of phenotypes. As well as consideration of the planting environment, effective plant selection for air pollution mitigation requires an understanding of the balance between beneficial and detrimental aspects of vegetation at species level and below. In the following subsections, we critically evaluate major findings regarding the costbenefit nature of species selection for urban air quality management.

\section{Disadvantageous aspects of Gl for air quality}

Beyond potential interruptions to atmospheric dispersion within the urban boundary layer ${ }^{56}$, vegetation can be a source of additional air pollutants, primarily in the form of biogenic volatile organic compounds (bVOCs) and pollen. Indeed, the negative impacts upon air quality associated with such emissions may counteract or even outweigh any intended pollution abatement ${ }^{40}$. In order to minimise any disadvantageous aspects, careful and contextual species selection is critical $^{42,57}$.

Biogenic volatile organic compounds. bVOC emissions from vegetation constitute a substantial global source of reactive hydrocarbon gases, including, most notably, isoprene, monoterpenes, and higher terpenoids ${ }^{58,59}$. bVOCs undergo atmospheric oxidation that, when combined with $\mathrm{NO}_{x}$, forms ground-level ozone $\left(\mathrm{O}_{3}\right)$, a noxious gas with acute and chronic impacts on human respiratory and cardiovascular systems ${ }^{60}$. Secondary organic aerosols can also be produced on oxidation, potentially increasing ambient PM concentrations, whose negative impacts on human health are well-supported ${ }^{1,61}$. bVOC emissions are generally low below $20^{\circ} \mathrm{C}$, but increase with temperature until peaking between $35^{\circ} \mathrm{C}$ and $40^{\circ} \mathrm{C}$ (plant species-specific), at which point emission rates stabilise and begin to diminish ${ }^{42}$. The incidence of bVOC emissions in the United Kingdom may therefore increase over the coming decades under projected climate change scenarios ${ }^{59,62}$.
High bVOC emissions are particularly problematic in urban areas (e.g. Ren et al. $^{63}$ ), where elevated temperatures and anthropogenic emissions converge ${ }^{38}$. bVOC emissions are also increased by other typical urban environmental stressors, including plant tissue damage by, for example, management interventions ${ }^{38}$. Plant tissue damage may instigate additional emissions in the form of green leaf volatiles ( $C_{6}$ aldehydes and ketones), implying the need to minimise pruning or other 'wounding events' (see 'Sustainability and species suitability'). Moreover, a recent review by Fitzky et al. ${ }^{59}$ suggests the potential for positive feedback in the form of plant tissue damage by $\mathrm{O}_{3}$. The restriction of overall bVOC emissions from urban GI is therefore $\mathrm{crucial}^{38}$, and may be achieved by judicious plant selection.

Given that the atmospheric reactivity of many bVOCs is higher than that of comparable carbon number anthropogenic VOCs, it is important to consider not only the total amount but the individual type of bVOCs emitted ${ }^{42,64}$. The emission of bVOCs that exhibit higher reactivity should be avoided first and foremost, particularly in near-road environments. For example, some sesquiterpenes can have a lifetime of just a few minutes, enabling the generation of secondary aerosols in the ambient air even where dispersion from the source is unhindered ${ }^{42}$. However, there is limited available information on the causes, means and rates of production of specific bVOCs by individual plant species ${ }^{59}$. Relevant studies have tended to focus on the two most abundant bVOCs (isoprene and monoterpenes; e.g. Benjamin and Winer ${ }^{65}$ ), yet up to a hundred different bVOC species bear considerable influences in the atmosphere ${ }^{66}$. A comprehensive review by Laothawornkitkul et al. ${ }^{66}$ investigated the role of bVOCs at the global scale and found that anthropogenic environmental changes, including climate change, may perturb the natural relationship between the biosphere and the atmosphere, resulting in an overall increase in future bVOC fluxes. Primary sources of isoprene and monoterpenes include several genera of common UK urban vegetation, such as Populus, Salix and Platanus (for isoprene), and Quercus, Malus and Pinus (for monoterpenes) ${ }^{66}$. Other reactive bVOCs and less reactive bVOCs (with atmospheric lifetimes of $<1$ day and $>1$ day, respectively) were grouped and categorised as such, and major emission sources of both were identified as grassland as well as typical urban vegetation genera, including Betula ${ }^{66}$.

Beyond genus, bVOC emissions can vary by several orders of magnitude between species $^{58}$. In a UK-based study, Donovan et al. ${ }^{40}$ developed an Urban Tree Air Quality Score (UTAQS) that ranks trees according to their potential for pollutant deposition versus bVOC emissions, based upon different modelled tree coverage and temperature scenarios. Resultant changes in $\mathrm{O}_{3}$ under each scenario were used to indicate that high bVOC emissions by some species lead to increased $(0.8-2.9 \%)$ regional $\mathrm{O}_{3}$, whereas other species facilitated a modest decrease $(0.3-0.8 \%)$ in $\mathrm{O}_{3}$ at the regional scale, due to a minimal increase in bVOC emissions relative to increased deposition ${ }^{40}$. Of the 30 tree species included in the study, 7 were found to have a 'low' UTAQS, defined as resulting in worsened air quality compared to the control scenario via increased concentrations $(<3 \%)$ of $\mathrm{O}_{3}$ and $\mathrm{NO}_{2}$ despite enhanced $\mathrm{HNO}_{3}$ deposition: Populus tremula, Quercus petraea, Quercus robur, Quercus rubra, Salix alba, Salix caprea and Salix fragilis ${ }^{40}$. These seven species are considered to be high isoprene emitters. The highest-scoring (i.e. most beneficial) species were found to be: Acer campestre, Acer platanoides, Alnus glutinosa, Betula pendula, Chamaecyparis lawsoniana, Crataegus monogyna, Larix decidua, Prunus laurocerasus and Pinus nigra ${ }^{40}$. These nine high-scoring species are low isoprene emitters, but it should be noted that some (e.g. Pinus nigra) can release significant amounts of monoterpenes ${ }^{40,66}$.

As average UK temperatures increase and while anthropogenic emissions remain high, the development of comprehensive bVOC emissions profiles for viable Gl species is recommended ${ }^{66}$. However, the strict classification of plant species as positive or 
negative according to bVOC emissions is highly problematic ${ }^{67}$, due in part to intraspecific variation under contrasting environmental conditions ${ }^{16,64}$. Indeed, Fitzky et $\mathrm{al}^{59}$. highlight that restricting the contribution of urban $\mathrm{Gl}$ to $\mathrm{O}_{3}$ formation is further complicated by uncertainty in the influences that new plants will bear on future urban environments. It is projected, for example, that plants selected for contemporary urban environments will reach maturity when anthropogenic $\mathrm{NO}_{x}$ concentrations are greatly reduced by the prevalence of cleaner transport, rendering bVOCs defunct as a precursor of $\mathrm{O}_{3}$ or, conversely, increasing the sensitivity of urban ozone chemistry to bVOC emissions ${ }^{59}$. Advanced air chemistry transport models that accommodate physiological models will be useful in describing bVOC-NO $-\mathrm{NO}_{3}$ relationships at different spatial scales, but such approaches to date have been incomplete ${ }^{59}$.

Pragmatic methods and principles, which encourage an overall restriction of bVOC emissions without absolute exclusion of certain plants, are therefore required (e.g. Simpson and McPherson ${ }^{67}$ ). Given that the majority of species are low bVOC emitting, with many presenting negligible or even indiscernible emissions ${ }^{64}$, the omission of species known to be generally high bVOC emitting may be sufficient for appropriate urban Gl selection in the United Kingdom. However, this consideration is primarily for large-scale (i.e. city- or regional-scale) planting initiatives ${ }^{28,65}$. At local scale, plant diversity with respect to existing or planned GI in surrounding local areas is considered to be more important for long-term resilience under a changing climate and urban landscape ${ }^{7,68}$.

Pollen. Pollen collectively describes individual pollen grains, which carry the male reproductive cells of a plant. In angiosperms, pollen is produced in the anther, whereas gymnosperms produce pollen in the male cone. Human allergic reactions to airborne pollen are $20 \%$ more likely in urban areas than in rural areas, due in part to species homogeneity and interactions between pollen emissions and existing air pollutants ${ }^{69,70}$. Cuinica et al. ${ }^{71}$ exposed pollen from three tree species (Betula pendula, Carpinus betulus and Ostrya carpinifolia) in vitro to two low levels of $\mathrm{NO}_{2}(\sim 0.034$ and $\sim 0.067 \mathrm{ppm}$ ), and found an associated increase in human allergenicity, as well as a significant decrease in pollen fertility. In a similar study, concerning the same species, Cuinica et al. ${ }^{72}$ found that exposure to low levels of $\mathrm{CO}, \mathrm{O}_{3}$ and $\mathrm{SO}_{2}$ can also increase the allergenicity of pollen, to varying degrees in respect of pollutant type, exposure time and plant species. These findings supplement numerous studies that indicate that the viability and chemical composition of pollen are altered by exposure even at very low levels ${ }^{73}$. However, it also appears that pollen is less susceptible when exposed to pollution in vivo, rather than in vitro, and that the susceptibility of pollen differs among plant species ${ }^{73}$. It may therefore be inferred that judicious plant selection can, to some degree, limit pollen corruption. However, further research into the influences of pollution on pollen dispersion and allergenicity is required, particularly under climate change and contrasting environmental scenarios ${ }^{70,73}$.

Male cultivars of dioecious species that rely upon wind pollination comprise the most prolific source of atmospheric pollen from woody plants ${ }^{41,74}$. The selection of species that do not fit this profile is therefore recommended for planting programmes that aim to improve air quality, particularly where vulnerable people (e.g. schoolchildren) spend their time ${ }^{74}$. This may include the selection of female cultivars or insect-pollinated species (although insects can struggle to pollinate in polluted areas ${ }^{75}$ ). However, it should be noted that species diversity is paramount, not only in order to support ecosystem resilience and multifunctionality but also to minimise the emissions potential of any individual species ${ }^{41}$.

A comprehensive guide to landscaping for limited allergenic pollen emissions is provided by Ogren ${ }^{74}$. This guide includes the
OPALS (Ogren Plant Allergy Scale) system, which currently ranks $>3000$ plants on a scale of 1 (least allergenic) to 10 (most allergenic) and according to $>130$ positive and negative factors. Ogren $^{74}$ anecdotally suggests that tall vegetation barriers on the windward side of properties may be used to limit the exposure of inhabitants to allergenic pollen. Such vegetation barriers should be constructed of species with low OPALS ratings, which excludes many species that are commonly used for hedging, including Arborvitae spp., Cupressus spp., Ligustrum spp., and male cultivars of Juniperus, Salix and Taxus spp. ${ }^{74}$.

\section{Advantageous aspects of Gl for air quality}

The primary mechanisms by which vegetation may be considered to improve air quality are those concerning dispersion and deposition $^{29}$. Dispersion involves the transportation and dilution of pollutants from the pollutant source, and the various roles that vegetation may play in this process were outlined earlier (see 'Local scale' subsection). Dry deposition describes the process by which pollutants are deposited on solid surfaces, thereby reducing ambient atmospheric concentrations. It is through its influences on deposition that vegetation may be seen as passively filtering pollutants from the ambient air. The capability of vegetation to do so is relatively high in light of its high surface area and complexity in comparison with, for example, grey infrastructure ${ }^{29,76}$. However, the potential capacity of a species for pollutant deposition is determined by the quality and sum of its individual traits ${ }^{36,37,77,78}$.

Numerous review articles and technical papers have discussed the dry deposition process, including deposition schemes used in modelling systems, as well as methods used to describe or define deposition, deposition velocity and deposited amount ${ }^{29,48,79,80}$. Significant points regarding the influences of $\mathrm{Gl}$ on dry deposition are summarised in Supplementary Section S1; the key message is that the influence of plant variation on deposition is largely determined by related variation in plant macromorphology and in the range of traits (including leaf physiology and micromorphology) that contribute toward surface resistance (Supplementary Section S1).

The immediate physical environment also influences the value and optimal form of $\mathrm{Gl}$ as a pollutant sink. Under field conditions, dispersion bears an inextricable influence on deposition ${ }^{20,77,81}$. Recognising this, a number of recent studies have employed various integrated dispersion-deposition approaches to investigate impacts of $\mathrm{Gl}^{52,82-85}$. For example, Morakinyo and $\operatorname{Lam}^{86}$ used such an approach in a CFD-based assessment of interactions between PM concentrations and vegetation barriers. The authors concluded that there may be trade-offs between vegetation barrier design for enhanced deposition and for enhanced dispersion ${ }^{86}$. Given the comparatively modest effects of deposition $^{82,84,87}$, dispersion should be prioritised under such circumstances. However, where $\mathrm{Gl}$ is appropriately positioned and managed, deposition is an important additional mechanism ${ }^{87}$.

\section{Vegetation traits for enhanced pollutant deposition}

Because the type and size of pollutant determine its means of deposition (Supplementary Section S1), different vegetation traits will be most effective for the deposition of different individual pollutants. A majority of studies have explicitly focussed on PM, and often only on particles $>1 \mu \mathrm{m}$ (Supplementary Table S1). Further research into the influences of individual plant traits on sub-micrometre PM and individual gaseous pollutant concentrations is highly recommended. However, empirical evidence from field experiments to date supports the generalisation drawn above that dry deposition to $\mathrm{Gl}$ is influenced by specific traits, or inherited biophysical characteristics, the most significant of which concern leaf surface area and leaf properties or functions ${ }^{32,36,88-90}$. As mentioned, generic recommendations regarding plant selection for pollution (particularly PM) abatement are provided by 
previous works (e.g. Yang et al. ${ }^{37}$, Grote et al. ${ }^{77}$ and Sæbø et al. ${ }^{36}$ ). Appropriate species choice may also be gleaned from outputs generated by ecosystem service forecast models, such as the increasingly popular i-Tree tools. However, such models and associated outputs currently offer limited applicability at local scale ${ }^{48}$.

Yang et al. ${ }^{37}$ developed a ranking system for 100 tree species and evaluated each according to presumed $\mathrm{PM}_{2.5}$ removal efficiency, potentially detrimental aspects, and environmental tolerances. Although the methodology used by Yang et al. ${ }^{37}$ has limitations (see 'Coordinated recommendations for enhanced vegetation barrier design'), the included set of determinant traits (particularly leaf complexity, size, surface feature and plant type (evergreen/deciduous)) is generally supported by findings from other studies. For example, Weerakkody et al. ${ }^{91}$ found a number of beneficial leaf traits for PM capture, including, most significantly, small size, complex shape and hairy or waxy surface. Earlier, Grote et al. ${ }^{77}$ found that foliage longevity is among the most important traits for air quality, along with canopy density, water-use strategy (an element of environmental tolerance) and bVOC emissions.

Foliage longevity and leaf phenology

Foliage longevity describes the length of time that a plant remains in leaf. Evergreen species retain functional leaves throughout the year, whereas deciduous species exist without functional leaves for part of the year and typically during the winter or dry season. The foliage longevity of deciduous species varies between and within species and is influenced not only by genotype but also by environmental conditions at microscale ${ }^{92}$. Due to the significance of leaves in pollutant deposition, the length of time during which Gl may be most influential upon deposition is determined by its foliage longevity. In terms of deposition, evergreen species are therefore preferable to deciduous species, and deciduous species that generally exhibit longer in-leaf seasons are preferable to deciduous species that generally exhibit brief in-leaf seasons ${ }^{20,36,93}$. However, evergreen species may be more susceptible to certain stressors (e.g. climate warming ${ }^{94}$ ) than deciduous species, with potential implications for sustainable ecosystem service provision.

Leaf phenology describes the timing of leaf emergence and senescence and is also subject to inter- and intraspecific variation according to genotype and environmental conditions ${ }^{92}$. Indeed, variation is such that some species (e.g. Faidherbia albida) exhibit 'reverse' leaf phenology, where emergence occurs when senescence would typically occur ${ }^{95}$. Such a feature may be useful in mitigating air pollution during wintertime, when urban pollutant concentrations are often highest ${ }^{36,42}$, without restricting the palette of potential species to those that are evergreen. Given a comprehensive understanding of local-scale pollutant fluxes over time, it may even be possible to select species according to the most suitable leaf phenology. However, the selection of a species according to such narrow criteria would be to disregard the complex relationship between $\mathrm{Gl}$ and air quality, as well as complementary services provided by $\mathrm{Gl}$, such as microclimate regulation during warmer seasons ${ }^{9}$. Furthermore, due consideration should be given to the suitability of each species to the anticipated environmental conditions. Many Pinus species, for example, are effective for PM deposition during wintertime, but susceptible to damage by salt spray from winter road conditioning, limiting their viability for many roadside locations ${ }^{36}$. The employment of alternative evergreen species that have exhibited tolerance to salt spray (such as Taxus spp.) may therefore be more appropriate at immediate roadsides ${ }^{36}$.

\section{Density and porosity}

The influence of a vegetation barrier on the movement of polluted air is determined by its density or, inversely, its porosity ${ }^{34}$. Abhijith et al. $^{20}$ and Janhäll ${ }^{29}$ both summarise research findings on the effects of leaf area index (LAl), leaf area density (LAD) and vegetation porosity on pollutant concentrations. LAI is a dimensionless metric that describes the total leaf surface area per unit ground area $\left(\mathrm{m}^{2} / \mathrm{m}^{2}\right)^{20,29}$. By contrast, LAD describes the total one-sided leaf area per unit canopy volume $\left(\mathrm{m}^{2} / \mathrm{m}^{3}\right)^{20,96}$. LAI and LAD are the primary density parameters used to describe the available vegetation area for deposition ${ }^{29}$, and one or the other parameter is often used to estimate barrier porosity ${ }^{34}$. Despite the uncertainty introduced by this estimation method, and the lack of comparability between results from different studies due to variation in methods used ${ }^{29}$, a number of generalisations may be drawn regarding the influences of porosity on downwind pollutant concentrations.

Where vegetation is healthy its density is determined by leaf and branching morphology ${ }^{41}$, which varies greatly between species. A recent field investigation into the influence of $\mathrm{Gl}$ in open-road conditions on $\mathrm{PM}_{10}, \mathrm{PM}_{2.5}, \mathrm{PM}_{1}, \mathrm{BC}$ and particle number concentration (PNC) found that downwind pollutant concentrations generally reduced with an increase in $L A D^{32}$. This inverse correlation is corroborated by results from a CFD modelling study undertaken by Tong et al. ${ }^{55}$, which compared the influences of six vegetation and/or solid barrier configurations on near-road particle pollutant concentrations. Tong et al. ${ }^{55}$ found that wide vegetation barriers with a high LAD, as well as vegetation-solid barrier combinations, significantly reduced downwind particle concentrations. However, results from these studies $^{32,55}$ suggest variation in concentration reduction efficiencies between particle sizes, which substantiates the conclusion by Steffens et al. ${ }^{97}$ that although reductions generally increase with the LAD of a barrier, the responses are non-linear. Similarly, based upon results from various studies, Abhijith et al. ${ }^{20}$ found that an optimal shelterbelt porosity may lie within the range of $20-40 \%$ for TSP and $10-20 \%$ for $\mathrm{PM}_{10}$, implying that optimal porosity is partly determined by target pollutant.

A higher vegetation barrier density generally results in lower downwind concentrations of both $\mathrm{PM}^{86,98,99}$ and gaseous pollutants ${ }^{54,100}$. However, CFD modelling undertaken by Ghasemian et al. ${ }^{54}$ found that a LAD of $3.33 \mathrm{~m}^{2} / \mathrm{m}^{3}$ reduced downwind concentrations of roadway emissions (represented by a tracer gas) by $10 \%$, whereas a LAD of $1 \mathrm{~m}^{2} / \mathrm{m}^{3}$ increased downwind concentrations by $15 \%$. These findings highlight that due to fluent penetration by pollutants and the introduction of the windbreak effect, very low-density (or very porous) vegetation barriers increase downwind pollutant concentrations until a critical point is reached at which further increases in LAD reduce downwind pollutant concentrations ${ }^{54}$. On the other hand, at very high densities (or low porosities), vegetation barriers can act as an impermeable obstacle, directing air above and around the barrier and restricting opportunities for pollutant deposition ${ }^{29,34}$. Therefore, optimal vegetation barrier density for deposition may be seen as permitting infiltration without throughflow ${ }^{101}$.

Abhijith et al. ${ }^{20}$ summarise that wide, tall and low-porosity vegetation barriers reduce downwind pollutant concentrations. The individual influences of these parameters (height, width and porosity), however, are relative not only to each other but to external factors. For example, meteorological conditions affect the porosity of different vegetation types in divergent ways; results from several studies indicate that, under high wind velocity, broadleaved and coniferous vegetation exhibit a decrease and an increase in porosity, respectively ${ }^{20,29}$. This reiterates the contextual nature of optimal porosity or density, as with all other aspects of GI. Barrier height, which should generally increase with distance from the road ${ }^{20}$, may be determined according to plant species choice or by planning requirements; barrier width is limited to available planting space; and optimal density can vary somewhat with barrier width ${ }^{34}$. In respect of the non-linear relationship between downwind pollutant concentrations and increasing 
$\operatorname{LAD}^{54,97}$, as well as the importance of semi-permeability ${ }^{101}$, optimal barrier density may be broadly described as above average density but below absolute. Given that the LAD of most naturally occurring vegetation is $1-5 \mathrm{~m}^{2} / \mathrm{m}^{3} 102$, and in line with findings by Ghasemian et al. ${ }^{54}$, a LAD of $\sim 4 \mathrm{~m}^{2} / \mathrm{m}^{3}$ may be recommended. Indeed, such a value would be in agreement with recent findings from CFD modelling undertaken by Deshmukh et al. ${ }^{53}$, which suggested that a LAD of $3 \mathrm{~m}^{2} / \mathrm{m}^{3}$ or higher is needed for downwind PM reductions. However, it should be noted that the density of a species that forms part of a barrier under active management may differ considerably from that exhibited by the same species under 'natural' or comparatively unmanaged conditions. Furthermore, the porosity of two barriers that contain the same species and are managed in the same way will differ according to site conditions (light availability, microclimate, soil conditions, root space, etc.). Therefore, it may be more feasible to regulate the porosity of a vegetation barrier by postplanting management interventions (e.g. thinning a hedge that is too dense) than by species choice alone, on the condition that the species chosen has a propensity to reach the required density (i.e. naturally exhibits at least a moderately dense crown).

\section{Leaf size and shape or complexity}

Differences in leaf size and complexity are significant predictors of deposition, particularly for $\mathrm{PM}^{91}$. Numerous field experiments have found that species with smaller leaves tend to be more effective than species with larger leaves, which may be partly attributed to the higher perimeter/surface area ratio of smaller leaves $^{103}$. For example, a recent study into leaf characteristics for traffic-related $\mathrm{PM}\left(\mathrm{PM}_{1}, \mathrm{PM}_{2.5}\right.$ and $\left.\mathrm{PM}_{10}\right)$ capture found that leaf size inversely correlated with PM accumulation, whereas there were no leaf surface characteristics that showed a clear correlation with PM accumulation across species ${ }^{104}$. Interestingly, this study found that the needles of Juniperus chinensis were the most effective leaves, despite being without leaf hairs or rough surfaces, followed by small-leaved broadleaf species ${ }^{104}$. This finding is supported by results from similar studies, which also found that coniferous (needleleaf) species generally offer higher deposition velocities than broadleaf species ${ }^{36,37,102,105,106}$. Sæbø et al. ${ }^{36}$ suggest that the long and narrow shape of needle leaves offer a thinner quasi-laminar boundary layer than that of broadleaves, which offers comparatively less resistance to deposition via a shortened diffusional path length ${ }^{107}$. Chen et al. ${ }^{105}$ concur that many conifers are generally more effective for PM accumulation and post-rainfall re-capture due to their acicular, needlelike shape.

For broadleaf species, Chen et al. ${ }^{105}$ found that leaf shape and venation did not affect PM deposition, but that micromorphological surface characteristics did. However, Leonard et al. ${ }^{78}$ found that leaf shape does influence PM deposition, albeit to a lesser extent than leaf surface characteristics. Indeed, a number of studies have found that complex leaf shapes are generally more effective than simple leaf shapes ${ }^{78,89-91,107}$. In an evaluation of leaf traits for PM deposition, Weerakkody et al. ${ }^{91}$ erected experimental rigs containing both synthetic and natural leaves alongside a busy road, including synthetic leaves of different shapes but with identical surface areas and surface characteristics. Weerakkody et al. ${ }^{91}$ found that complex (lobed) leaf shapes demonstrated a greater potential for PM deposition than simple (elliptical or linear) leaf shapes. The authors suggest that differences in the effectiveness of leaf shapes are related to the influences of leaf shape on air patterns around the leaf, as a result of the variable drag forces upon the leaf due to wind conditions ${ }^{91}$. The comparatively poor accumulation on elliptical leaves, despite their larger perimeter, is explained by their pliancy under wind flows and lower levels of associated turbulence, indicating that the rigidity of needle leaves may be significant in their effectiveness for deposition ${ }^{91}$. A comparison of results from several wind tunnel studies concerning particle capture efficiencies of different species, formulated by Conroy et al. ${ }^{108}$, found that Pinus nigra and Cupressocyparis leylandii were the first and second (respectively) most effective species under wind speeds of $3 \mathrm{~m} / \mathrm{s}$, but that Pseudotsuga menzeisii was the least effective species, behind nine broadleaf species. These findings highlight that it cannot be concluded that needle leaves are necessarily more effective for deposition than broadleaves. However, for PM deposition, it may be generalised that needle-like and small, complex leaves are more effective than other leaf types. Further research into the comparative effectiveness of different coniferous leaf shapes (needle-like, awl-shaped, scale, etc.) is highly recommended.

\section{Leaf surface features}

Several leaf surface features are considered to positively influence deposition. Plants whose leaves present one or more of these features, as well as any of the above-described biophysical traits, are therefore considered to be relatively effective. However, functional traits may vary substantially not only between but within species, according to microclimatic and environmental conditions $^{77,92}$. Additionally, the functionality of any individual trait under any given circumstance is subject to internal or plantspecific factors, such as phenology, as well as external factors, such as ambient temperature ${ }^{109}$.

Generally, rough leaf surfaces are more effective for deposition than smooth surfaces $36,88,91,103,107,110,111$. For example, Weerakkody et al..$^{91}$ reported a number of beneficial traits for PM capture, including, most significantly, small leaf size and complex leaf shape (macromorphological features, discussed above), as well as trichomes, epicuticular wax and surface ridges (micromorphological features). An earlier study undertaken by Zhang et al. ${ }^{111}$ utilised atomic force microscopy and scanning electron microscopy to examine influential leaf features for particle capture, and found the same micromorphological features to be significant for deposition. However, Zhang et al. ${ }^{111}$ observed a difference in significance of individual features between broadleaved and coniferous species: increased leaf micro-roughness (characterised by grooves and ridges on the leaf surface) was found to correlate with increased deposition to broadleaves, whereas stomatal density and amount of epicuticular wax were found to positively correlate with deposition to coniferous (needle) leaves. These findings were corroborated by a similar, subsequent study ${ }^{112}$.

Epicuticular wax ultrastructures were also found to be significant in PM deposition to both conifers and broadleaves by a number of other studies ${ }^{36,90,103,113}$. Grote et al. ${ }^{77}$ suggest that this may be partly due to leaf wettability, with particle concentrations significantly reduced through reactions with wet surfaces, and water-soluble pollutants such as $\mathrm{NO}_{2}$ and $\mathrm{SO}_{2}$ subject to dissolution in a water film at the leaf surface. However, the influence of wax structure and chemical composition on variation in deposition is not well understood and requires further research ${ }^{113,114}$.

There is also uncertainty in the comparative significance of stomatal traits, with disagreement between findings that indicate the importance of stomatal density (e.g. Zhang et al. ${ }^{111}$ ) and those that indicate the importance of stomatal size (e.g. Liang et al. ${ }^{115}$ ). Stomatal uptake particularly concerns the diffusion of gaseous pollutants from the air as a result of plant photosynthetic and water management processes ${ }^{116}$, although particles $<2 \mu \mathrm{m}$ can enter the stomatal cavity ${ }^{110}$. Stomata open and close in response to environmental conditions, and air pollutant removal may be enhanced by the selection of species with extensive opening periods (anisohydric species, which include Populus and some Quercus species) rather than species that shorten their stomatal opening period in response to drought (isohydric species, which include Pinus and Platanus species) ${ }^{77}$. However, the benefit of 
plants that exhibit the appropriate water-use strategy may be offset in some cases by increased susceptibility to harsh urban conditions (see 'Environmental tolerance').

Regarding the above results by Weerakkody et al. ${ }^{91}$ and Zhang et al. ${ }^{111}$, a link between leaf grooves and/or trichomes and effective particle capture is well-supported by the literature ${ }^{36,88,90,105,113,117,118}$. Chen et al. ${ }^{105}$, for example, found a clear correlation between $\mathrm{PM}_{2.5}$ accumulation and grooves and trichomes in leaves. This is supported by a chamber study, which compared deposition velocities across five plant species (see Supplementary Table S1) and found that certain leaf features, including grooves and trichomes, improved particle capture for $\left(\mathrm{NH}_{4}\right)_{2} \mathrm{SO}_{4}{ }^{117}$.

Both Weerakkody et al. ${ }^{91}$ and Leonard et al. ${ }^{78}$ conclude that trichomes are the most effective micromorphological feature for particle deposition. Liang et al. ${ }^{115}$ found instead that groove proportion and stomata size positively correlate with $\mathrm{PM}_{2.5}$ capture amount, whereas trichomes and stomatal density were not found to be significant. Disagreement between these and other findings highlights that the single most influential surface feature across leaf types (broadleaf, needle-like, scale-like, etc.) for individual pollutant types is currently unclear and an area for further research ${ }^{118}$. However, it may be generalised that rough leaf surfaces (including grooves, ridges and trichomes) are more beneficial than smooth surfaces for particle deposition, that epicuticular wax is beneficial (particularly for deposition to conifers $^{111,112}$ ) and that stomatal traits play a significant role that warrants further investigation. These points conform to different processes outlined in Supplementary Section S1, which highlights that different surface features will vary in influence for different target pollutants.

Findings from a recent study undertaken by Zhang et al. ${ }^{119}$ indicate that genetic modification may enable the selection and enhancement of micromorphological features for air pollution removal, as previously suggested by Lawson and Blatt ${ }^{116}$. Due to their complex leaf surface micromorphology, broadleaf species are more effective for deposition than coniferous species per leaf area, whereas coniferous species are more effective at tree scale due to a larger total leaf area ${ }^{110,115}$. However, Tiwary et al. ${ }^{120}$ illustrate that deposition does not necessarily increase with leaf area for all pollutant types, that a range of different processes, counterprocesses and feedback mechanisms are at all times in operation, and that holistic species assessment systems are therefore required.

\section{SUSTAINABILITY AND SPECIES SUITABILITY}

To minimise any potential trade-offs, it is necessary to understand the suitability of each considered plant species to the environmental conditions of the intended planting site. In a review of the multiplex effects of urban vegetation on air quality, Leung et al. ${ }^{57}$ conclude that a holistic approach to $\mathrm{Gl}$ design is required in order to ensure long-term benefits. Considerations include environmental tolerance and ecophysiology, both of which are discussed below. However, to support plant health, additional site-specific information must be taken into account when utilising a species selection guide. Such information would include soil conditions, root and crown growth space, the likelihood of de-icing salt spray and other environmental factors relevant to plant health and with regards to the particular stresses of urban conditions ${ }^{41,120}$.

The support of plant health, by judicious selection and $\mathrm{Gl}$ management, minimises interruption to the provision of any air pollution mitigation services, and maximises each plant's capacity for such services ${ }^{2,121}$. For example, pollutant removal via leaf stomatal conductance is reduced, and bVOC emissions are potentially increased, when plants are stressed ${ }^{45,122}$. However, the support of plant health is also important in order to minimise costs (in both monetary and environmental terms) associated with plant establishment and management. Plant death generates emissions through decomposition ${ }^{57}$ and through anthropogenic emissions associated with replacement, a significant amount of which may have otherwise been reduced or avoided by appropriate species selection ${ }^{121,123}$. Furthermore, the creation of gaps in a vegetation barrier due to plant death could be detrimental to pedestrian-side air quality, with increased pollutant concentrations downwind caused by the aforementioned effects of barrier porosity on airflow.

\section{Environmental tolerance}

Urban roadside environments present extremely stressful conditions for vegetation ${ }^{41,120,124}$. In outlining a performance evaluation framework for urban GI development, Tiwary et al. ${ }^{120}$ suggest that a plant's tolerance of relevant environmental stresses should be given priority over all other functionalities as an indicator of its suitability. This point is supported by findings from numerous studies into aspects of successful plant establishment in urban areas, all of which support the principle that the viability of individual species varies with planting site conditions ${ }^{41,68,123,125-127}$.

Environmental conditions vary considerably between sites at all scales. This is especially true of urban environments, where unnatural topographies and physical infrastructure can present an extreme heterogeneity of ground conditions and climates at local scale ${ }^{68,128}$. However, typical stressors in roadside environments include: pests and diseases; dry or nutrient-poor soil conditions; soil compaction and root space restrictions; crown growth restrictions; waterlogging; salt pollution associated with winter road conditioning; and air pollution $41,68,120,123,124$.

Plant diversity is crucial to urban forest resilience, and pest and disease outbreaks pose a significant threat to what is often a limited assemblage of tree species in European cities ${ }^{68}$. Indeed, Tiwary et al. ${ }^{120}$ highlight that more than half of all street trees across Europe comprises just three to five genera, including Acer, Aesculus, Platanus and Tilia. Sjöman et al. ${ }^{68}$ conclude that urban tree planting schemes should be open to the inclusion of nonnative species, where ecologically appropriate, in order to ensure the survival of diverse plants in paved environments, which are characterised by dry soil conditions under impervious surfaces and warm microclimates due to solar energy absorption. Findings from a study undertaken by Roman et al. ${ }^{123}$, in California, USA, appear to corroborate this characterisation of typical planting conditions in temperate urban areas. By monitoring plant survival over five years as part of a tree give-away scheme, Roman et al. ${ }^{123}$ found that five-year survival was partly attributable to low water-use demand in certain species, as well as stable home ownership and tree aftercare. Sade et al. ${ }^{129}$ suggest that an anisohydric water-use strategy may be beneficial when water is available and under moderately stressful conditions, but that isohydric behaviour may offer greater resistance under extreme stress (i.e. drought). This observation supports the selection of anisohydric plants for enhanced stomatal uptake of pollutants, except where prolonged periods of soil water deficiency are projected to occasionally occur. Alternatively, and with a focus on continued ecosystem service provision under dry urban conditions, Sjöman et al. ${ }^{130}$ recommend the selection of species that employ drought tolerance mechanisms as opposed to water loss avoidance strategies. Sjöman et al. ${ }^{130}$ present leaf water potential at turgor loss as a reliable measure of a plant's ability to maintain physiological function during drought conditions. Speciesspecific datasets based on this measure were used where possible to inform the primary source for the drought tolerance factor in Table $4^{41}$.

To determine a plant's viability, it is important to consider the specific environment of each proposed planting site ${ }^{121}$. Unlike other environmental stressors, however, it is inherent that the 
stressor of air pollution is present where plants are to be selected for the purpose of air pollution mitigation. Air pollution tolerance is therefore the only plant trait that may not be selected for on an ad hoc basis, but which should instead be exhibited by every plant to be considered, albeit to varying degrees according to context. For example, although Pinus species are considered to be particularly effective for PM collection, degradation of epicuticular waxes in Pinus needles by air pollution has been observed in several studies, suggesting that Pinus species may lack long-term viability at heavily polluted sites ${ }^{36,131,132}$. Similarly, plants with low stomatal conductance can tolerate relatively high levels of gaseous pollution, but are inefficient for gaseous pollutant removal, and may therefore be better suited to locations where PM attenuation is a significant focus ${ }^{93}$. Micromorphological structures around stomata, including waxy rings and cuticular arches, may also help to protect plants against PM pollution, although further research into this is needed ${ }^{112}$.

Major phytoxic air pollutants include $\mathrm{O}_{3}, \mathrm{SO}_{2}$ and $\mathrm{PM}$, and damage is primarily presented by leaf abnormalities ${ }^{133,134}$. However, gaseous pollutants are very quickly metabolised unless photosynthesis and membrane permeability are damaged, which means that stomatal uptake remains high while the plant remains healthy and that pollution tolerance may therefore be considered a trait that influences gaseous pollutant removal ${ }^{77}$. Numerous studies have employed an Air Pollution Tolerance Index (APTI) based on leaf attributes that are associated with greater tolerance of air and water pollution stress ${ }^{120,135-144}$. APTI requires the determination of four biochemical parameters at leaf level, which are then subjected to a formula (Eq. 1) developed by Singh and Rao $^{145}$ :

$\mathrm{APTI}=\frac{A(T+P)+R}{10}$

where $A$ is the ascorbic acid content $(\mathrm{mg} / \mathrm{g}), T$ is total chlorophyll $(\mathrm{mg} / \mathrm{g}), P$ is leaf $\mathrm{pH}$ and $R$ is the relative water content (\%). Plants with APTI values of $\leq 11$, between 12 and 16 , and $\geq 17$ are broadly classified as sensitive, intermediately tolerant or sensitive, and tolerant of air pollution, respectively ${ }^{136}$.

This method has been used to estimate air pollution tolerance for different species around the world. However, such studies have predominantly involved specimens whose provenance differs in environmental conditions (climate, soil water and/or nutrient content, and ambient air pollution concentrations) from those of typical urban planting sites in the United Kingdom ${ }^{134-138,140-144}$. Where the above APTI method has been applied in the United Kingdom (e.g. Tiwary et al. ${ }^{120}$ ) or under comparable conditions (e.g. Nadgórska-Socha ${ }^{139}$ ), the studied range of species has been limited, and this review found no single APTI dataset for the suggestion of species relevant to UK urban sites that offers sufficient diversity. The air pollution tolerance of individual species for UK planting schemes must therefore be inferred from observation or practitioner experience ${ }^{41}$. However, air pollution damage is diverse in effects, and different species exhibit different tolerances to different types and quantities of specific pollutants, with variation in tolerance due to variation in any of the four biochemical parameters measured (Eq. 1), implying that a standardised APTI dataset may be problematic or misleading in any case $^{41,133,134,136}$.

\section{Plant morphology and ecophysiology}

The morphology of a plant concerns its physical form and structure as a component of its phenotype. For the purposes of this review, morphology is discussed in terms of external or readily observable characteristics, with a particular focus on whole plant size and form, rather than, for example, leaf micromorphology. The size and structural form of Gl with respect to its surrounding physical environment influence its impact upon ambient air quality, and the expected morphology of a species should therefore be considered on a site-by-site basis to ensure effectiveness as well as plant health ${ }^{7,32}$. Plant ecophysiology concerns the relationship between the exhibited traits or physiology of a given plant species and its habitat preferences or geographical distribution ${ }^{41}$. Known ecophysiological features of a species may thereby be utilised to indicate its likely suitability for a planting site ${ }^{41}$. The subsequent text exclusively concerns the selection of plants for improved urban air quality according to morphological and ecophysiological characteristics.

\section{Morphology}

The projected growth form of a species may indicate its suitability for the appropriate barrier shape given the surrounding built environment. For example, a medium-sized and lighter-crowned tree may be suitable in shallow street canyons, whereas a more compact shrub may be more suitable in deeper street canyons (Table 2). Under open-road conditions, species capable of forming a tall, dense barrier with foliage from ground level are most suitable where planting space is restricted; where space allows, two or more complementary species may be planted strategically together, such as a low-growing species (with air pollution and salt tolerance) at the roadside that is followed by rows of taller vegetation $^{32,34}$.

Considering anticipated size or form at maturity can support plant health (e.g. by ensuring that appropriate growth space is available ${ }^{124}$ ) and thereby support effective and sustainable ecosystem service provision ${ }^{41,93}$. Moreover, species whose growth patterns naturally conform to the desired $\mathrm{Gl}$ shape will require less maintenance, which in turn will minimise both monetary and environmental cost (e.g. due to bVOC emissions). However, some formative pruning and similar post-planting interventions, where applicable, will support the development of an appropriate and healthy form, potentially reducing long-term maintenance costs associated with, for example, tree replacement ${ }^{41,123}$. It is also worth noting that although species (and particularly cultivars) may be broadly categorised by typical size or form at maturity, such aspects vary somewhat as a function of environment, and are influenced by site-specific conditions including wind exposure or light availability ${ }^{41}$.

\section{Ecophysiology and succession}

Urban planting sites are subject to a variety of environmental stresses as well as climatic and microclimatic conditions that are atypical of natural or rural areas of the same region ${ }^{146}$. This deviation complicates plant selection for such sites, with plants that may be described as native or even of local provenance potentially rendered unsuitable ${ }^{68}$. An understanding of the ecophysiology of a species can aid in anticipating its likely viability for a site ${ }^{41}$, and as already outlined, plant health is paramount in the effective performance of Gl for air pollution mitigation.

Succession is the natural process of change in the species structure of an ecological community over time. Forest succession is often generally predictable for a given community and includes the order in which different species tend to become established in new areas or following an event that creates a clearing. Early successional species, such as Betula pendula, generally thrive in open sites that may be characterised by conditions of high light and wind exposure and poor soil quality ${ }^{41}$. Late successional species, such as Fagus sylvatica, tend to be shade tolerant and thrive in humid conditions with nutrient-rich soil; these species are generally capable of eventually out-growing early successional species of their respective communities ${ }^{41}$. Recognising the successional status of individual species for selection will optimise $\mathrm{Gl}$ establishment success rates ${ }^{41}$, which, in turn, will minimise emissions, such as from re-planting and aftercare. 


\section{COORDINATED RECOMMENDATIONS FOR ENHANCED VEGETATION BARRIER DESIGN}

Whereas the optimum physical dimensions of grey infrastructure can be calculated and manufactured to a highly specific standard, vegetation barriers are fluid entities that require careful consideration not only of the costs and benefits of each particular species but also of its suitability to the proposed planting site. To aid this process, Tables 3 and 4 present an initial investigation into viable woody plant species for vegetation barriers, with a particular focus on urban environments in the United Kingdom. A decision support tool developed by Hirons and Sjöman ${ }^{41}$ was selected as the principal source for two reasons: (i) it was created by investigating species that are currently used in urban forestry, as well as species whose ecoregion is similar in constraints to those of typical urban planting environments; and (ii) it contains internally consistent, species-specific information on several factors that had been identified as significant in air pollution mitigation, such as environmental tolerances and morphological characteristics.

For reasons outlined under 'Environmental tolerance' and 'Species selection', observed air pollution tolerance was the only prerequisite by which species were shortlisted for inclusion. Similarly, due to the established objective- and contextdependency of effective GI design, it was decided not to employ a ranking system (e.g. Yang et al. $^{37}$ ) for species or for the considered factors, but instead to present information on a range of factors whose relative significance may be determined by the user. Supplementary Table S2 explains the categorisation of each factor and the primary sources used. Supplementary Section S2 also provides further information regarding the construction, terminology and limitations of Tables 3 and 4.

Colour-coding was initially considered in order to highlight species designated: (i) potentially useful for street canyons as lowlevel vegetation (e.g. due to small size at maturity and with a moderate- or high-density crown; Table 2); (ii) potentially useful for street canyons as high-level vegetation (e.g. due to small or medium size at maturity and a light crown; Table 2); or (iii) suitable or commonly used for hedging (e.g. see Gilman and Watson ${ }^{147}$ ). However, it was instead decided that employing a colour-coding system may unintentionally suggest that recommendations are dichotomous. Trees categorised as 'moderate density', for example, may in fact be pruned to offer a lighter or more 'open' crown. Similarly, trees that are categorised as having a 'large' mature size may in fact be slow-growing species that respond well to pruning, such as Taxus baccata, which can often be readily shaped according to objectives. Indeed, growth rate is an important additional factor that should be considered when selecting species for air pollution abatement. Other factors to consider, some of which may have been included in Table 3 or 4 had data been available, include: species tolerance of other environmental stresses (i.e. beyond salt and drought); leaf phenology (matching complementary species may enable more consistent air pollution mitigation over the year); leaf stomatal traits (for UFP and gaseous pollutant uptake); and other parts of the plant (e.g. the petioles and bark of Rhus typhia are characterised by velvety, grey hairs, which no doubt influence its value for particle deposition).

Further research into each species should be undertaken before implementation in order to avoid potential trade-offs with ecosystem services other than air pollution mitigation ${ }^{45}$. Furthermore, there may be trade-offs between intraspecific traits that influence the overall benefit of a species (e.g. the literature indicates that $T$. baccata may be a beneficial species, because it is evergreen, needleleaf, has a high LAI and can be readily trained into particular dimensions, but it may be that $T$. baccata is too dense for optimal infiltration of pollutants ${ }^{29}$. Similarly, trade-offs exist between the selection of evergreen broadleaved, evergreen conifer, deciduous broadleaved and deciduous conifer species, with needleleaf species offering a higher surface area per plant, broadleaf species generally offering a greater number of beneficial surface characteristics per leaf area, evergreen species offering year-round benefits (or costs, conversely) and deciduous species offering greater dispersion in street canyons in winter.

Optimal vegetation barrier composition for air pollution mitigation is a function of innumerable factors, some of the most recognised of which are reflected in Tables 3 and 4. The included species therefore require testing under field conditions. Different pollutants are influenced in different ways by different species and combinations of species, and according to site-specific conditions. Ensuring that the selected species contain a combination of beneficial traits can significantly improve deposition ${ }^{78}$, and incorporating a mix of different species where possible can help to target different pollutant types.

Unfortunately, the decision to form the initial species list from those that had some observed air pollution tolerance noted in Hirons and Sjöman ${ }^{41}$ meant that a great number of viable and well-established species for screening (such as Fagus sylvatica, Carpinus betulus, llex aquifolium, Buxus sempervirens, etc.) were not included. This species list should be expanded to include an increasing number of species and as further research data becomes available. Improving plant diversity in urban areas is imperative for increased urban ecosystem resilience to environmental hazards including and beyond air pollution ${ }^{7,11,68}$. Furthermore, several studies have demonstrated that diversity not only in species but in vegetation type and structure is important for air quality, carbon sequestration and the sustainable provision of diverse ecosystem services ${ }^{128,130,148}$. Discouragement of monoculture planting is another reason for which it was decided that the species in Tables 3 and 4 would not be ranked.

The individual leaf surface descriptions used in Table 3 were limited by an ostensible unavailability of detailed and internally consistent data on the micromorphology of all species concerned. Further research into the leaf micromorphology of different plants that may be viable for temperate urban environments is highly recommended. Moreover, it is recommended that where studies are undertaken on the influence of micromorphology on, for example, deposition, the associated species-specific data should, where feasible, be made readily available. Although such datasets on epicuticular wax structures were found to be available (e.g. Tomaszewski and Zieliński ${ }^{149}$ ), it was decided not to include this data in Table 3 for the sake of practicality, given that the relative influence of different epicuticular wax structures remains uncertain.

\section{Species selection}

The species list underpinning Tables 3 and 4 offers an initial investigation into relevant species and is not exhaustive. Additional species (i.e. not included in these two tables) should be considered, given that the relevant parameters are met. Figure 1 provides a schematic representation of the species selection process that may be undertaken. The final column in Fig. 1 contains a limited series of points to consider when finally selecting for beneficial plant traits. For brevity, these points are highly simplified; for example, 'evergreen > deciduous' should ideally be graded to reflect that evergreen species are generally more beneficial than deciduous species with longer in-leaf seasons, which are generally more beneficial than deciduous species with brief in-leaf seasons. The diagram was constructed with PM in mind, but other features (e.g. stomatal characteristics) may be more significant for gaseous pollutants. As the final column heading indicates, each point should be considered according to site-specific needs or constraints. For example, a narrow planting site may necessitate a species with a higher crown density, whereas a site that offers ample opportunity for 


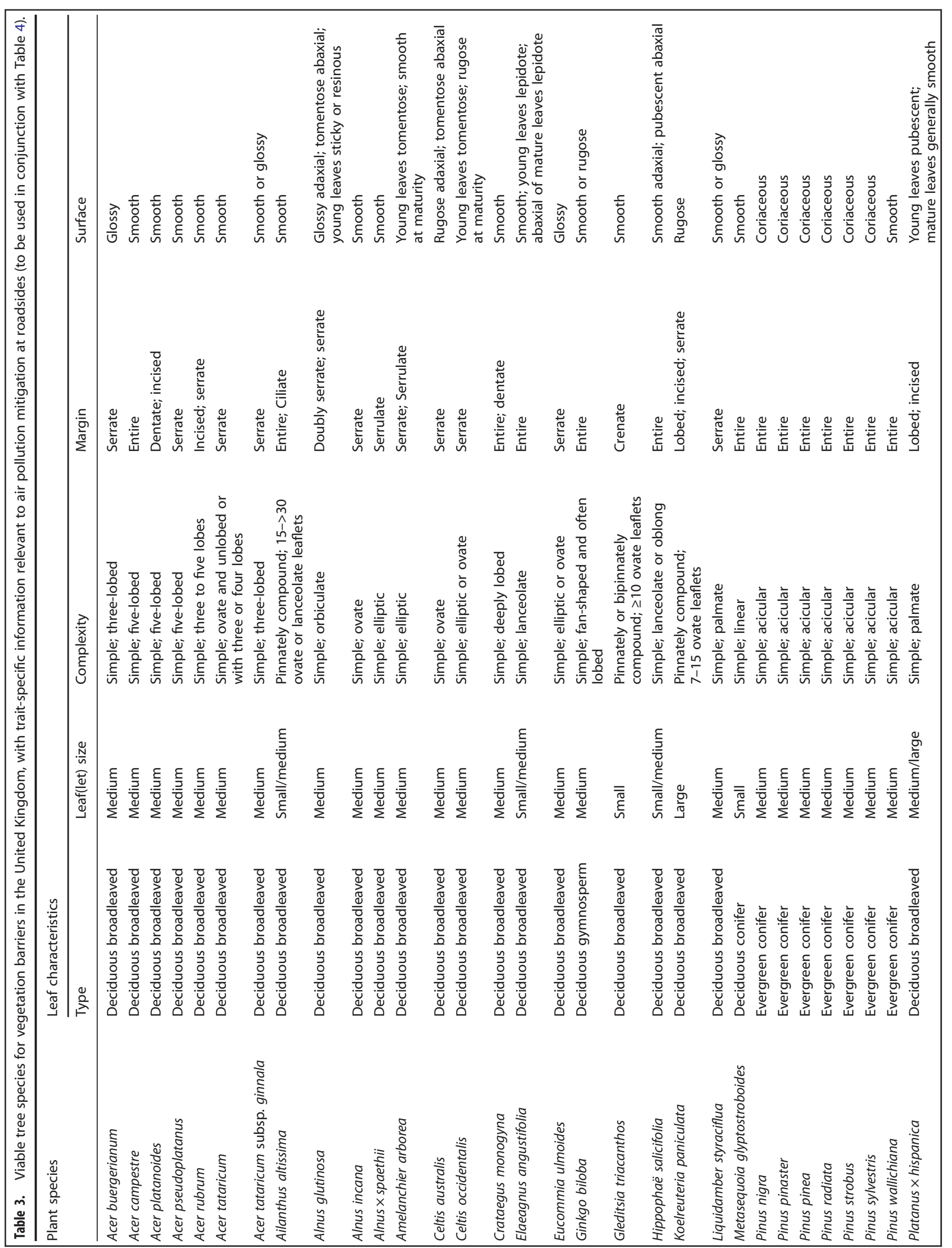




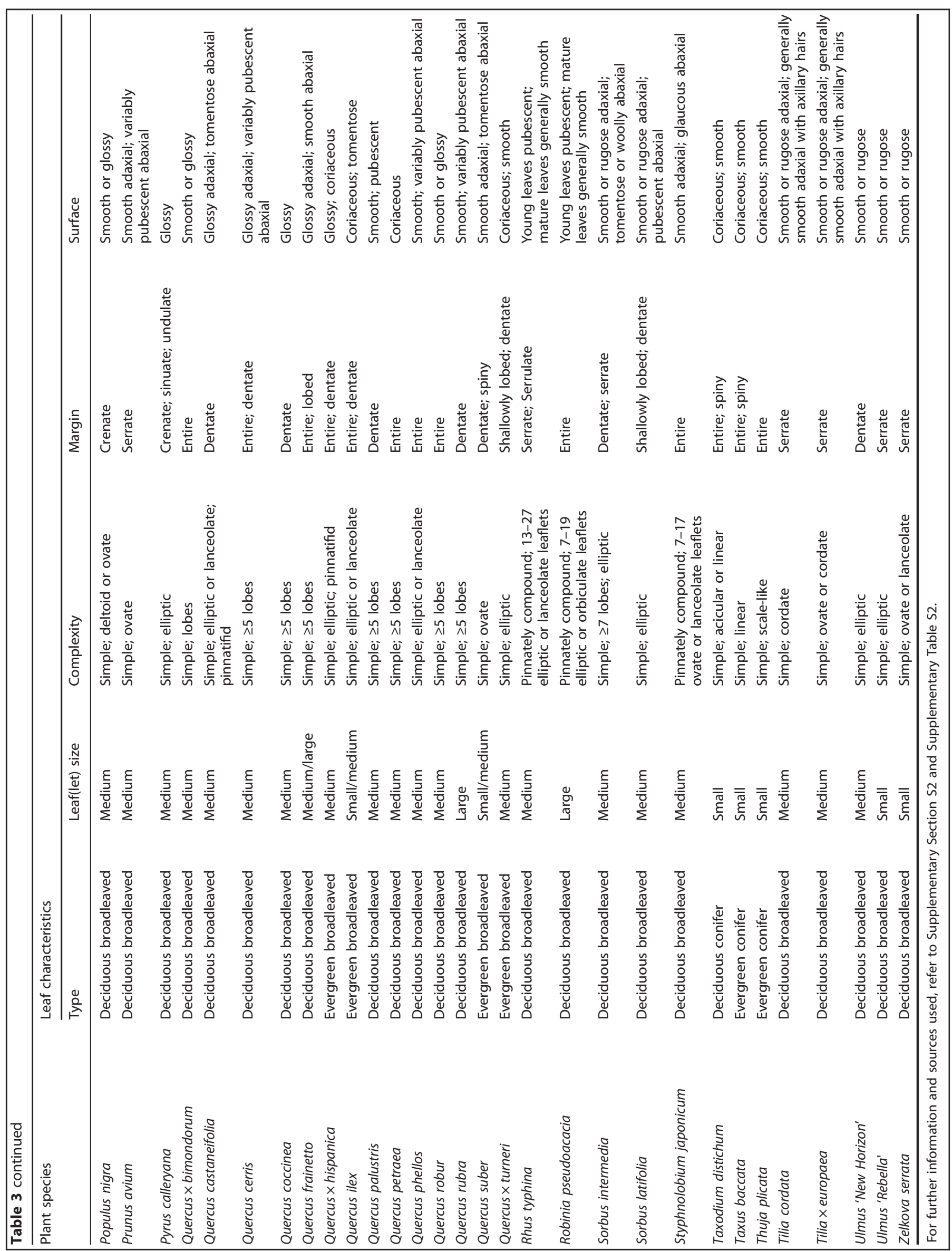


Table 4. Viable tree species for vegetation barriers in the United Kingdom, with trait-specific information relevant to air pollution mitigation at roadsides (to be used in conjunction with Table 3).

\begin{tabular}{|c|c|c|c|c|c|c|c|}
\hline Plant species & \multicolumn{2}{|l|}{ Morphology } & Successional status & \multicolumn{2}{|l|}{ Tolerances } & \multicolumn{2}{|c|}{ Emissions } \\
\hline Acer buergerianum & Large & Dense & - & Moderately tolerant & Yes & Low & Moderate \\
\hline Acer platanoides & Large & Dense & Late & Moderately tolerant & No & Low & High \\
\hline Acer pseudoplatanus & Large & Dense & Late & Moderately sensitive & No & Low & High \\
\hline Acer tataricum subsp. ginnala & Small & Dense & Late & Moderately tolerant & Yes & Low & Moderate \\
\hline Ailanthus altissima & Massive & Moderate & - & Tolerant & Yes & Low & Moderate (var.) \\
\hline Alnus glutinosa & Large & Open & Early & Moderately sensitive & Yes & Low & High \\
\hline Alnus incana & Large & Open & Early & Moderately sensitive & Yes & Low & High \\
\hline Alnus $\times$ spaethii & Large & Moderate & Early & Moderately sensitive & Yes & Low & High \\
\hline Crataegus monogyna & Small & Dense & Early & Tolerant & Yes & Low & Low \\
\hline Elaeagnus angustifolia & Medium & Moderate & Early & Tolerant & Yes & Low & High \\
\hline Eucommia ulmoides & Large & Moderate & - & Tolerant & Yes & Low & High (var.) \\
\hline Ginkgo biloba & Large & Moderate & - & Tolerant & Yes & High & Moderate (var.) \\
\hline Gleditsia triacanthos & Large & Open & Early & Tolerant & Yes & Low & Moderate (var.) \\
\hline Hippophaë salicifolia & Small & Moderate & - & Moderately tolerant & Yes & Low & Moderate (var.) \\
\hline Koelreuteria paniculata & Large & Moderate & Early & Tolerant & Yes & Low & Low \\
\hline Liquidamber styraciflua & Large & Moderate & Early & Moderately tolerant & Yes & High & Moderate \\
\hline Metasequoia glyptostroboides & Massive & Moderate & Early & Moderately tolerant & No & Low & Low \\
\hline Pinus nigra & Massive & Dense & Early & Tolerant & Yes & Low & Low \\
\hline Pinus pinaster & Massive & Dense & Early & Moderately tolerant & Yes & Low & Low \\
\hline Populus nigra & Massive & Moderate & Early & Sensitive & Yes & High & High (var.) \\
\hline Prunus avium & Large & Moderate & Early & Moderately sensitive & No & Low & Low \\
\hline Pyrus calleryana & Medium & Dense & - & Tolerant & Yes & Low & Low \\
\hline Quercus $\times$ bimondorum & Medium & Dense & - & Moderately tolerant & Yes & High & High \\
\hline Quercus castaneifolia & Massive & Dense & Early & Moderately tolerant & Yes & High & High \\
\hline Quercus cerris & Massive & Moderate & Early & Tolerant & Yes & High & High \\
\hline Quercus coccinea & Massive & Moderate & Early & Tolerant & Yes & High & High \\
\hline Quercus frainetto & Massive & Moderate & Early & Tolerant & Yes & High & High \\
\hline Quercus $\times$ hispanica & Massive & Moderate & - & Tolerant & Yes & High & High \\
\hline Quercus ilex & Large & Dense & - & Tolerant & Yes & High & High \\
\hline Quercus palustris & Large & Moderate & Early & Tolerant & Yes & High & High \\
\hline Quercus petraea & Massive & Moderate & - & Moderately tolerant & Yes & High & High \\
\hline Quercus phellos & Large & Dense & - & Moderately tolerant & Yes & High & High \\
\hline Quercus robur & Massive & Moderate & Early & Moderately tolerant & Yes & High & High \\
\hline Quercus rubra & Massive & Moderate & Early & Moderately sensitive & Yes & High & High \\
\hline Quercus suber & Large & Dense & - & Tolerant & Yes & High & High \\
\hline Quercus $\times$ turneri & Medium & Dense & - & Moderately tolerant & Yes & High & High \\
\hline Rhus typhina & Small & Moderate & Early & Moderately tolerant & Yes & Low & High (var.) \\
\hline Robinia pseudoacacia & Large & Open & Early & Tolerant & Yes & Low & Moderate \\
\hline Sorbus intermedia & Medium & Moderate & - & Moderately tolerant & Yes & Low & Low \\
\hline
\end{tabular}




\begin{tabular}{|c|c|c|c|c|c|c|c|}
\hline \multirow[t]{2}{*}{ Plant species } & \multicolumn{2}{|l|}{ Morphology } & \multirow[t]{2}{*}{ Successional status } & \multicolumn{2}{|l|}{ Tolerances } & \multicolumn{2}{|c|}{ Emissions } \\
\hline & Mature size & Canopy density & & Drought & Salt & bVOCs & Pollen \\
\hline Styphnolobium japonicum & Large & Moderate & Early & Moderately tolerant & Yes & High & Low \\
\hline Taxodium distichum & Massive & Moderate & - & Moderately sensitive & Yes & Low & High \\
\hline Tilia cordata & Massive & Moderate & Late & Moderately sensitive & No & Low & Moderate \\
\hline Tilia $\times$ europaea & Massive & Moderate & Late & Moderately sensitive & No & Low & Moderate \\
\hline Ulmus 'New Horizon' & Large & Moderate & Early & Moderately tolerant & No & Low & - \\
\hline Ulmus 'Rebella' & Large & Moderate & - & Moderately tolerant & No & Low & - \\
\hline Zelkova serrata & Large & Moderate & Early & Moderately tolerant & Yes & Low & High \\
\hline
\end{tabular}

A dash (-) indicates a lack of available data. For further information and sources used, refer to Supplementary Section S2 and Supplementary Table S2.

rows of trees parallel to the road may allow for species with more open crowns to be chosen, broadening the palette of potential species and permitting a focus on other traits, such as leaf surface features (Table 3).

Due to the extremely stressful planting conditions found in urban environments and along roadsides, we suggest a rationale of negative selection, in order to deduce a base list of suitable candidates, before finally employing positive selection for species that are expected to enhance deposition. This rationale conforms with the principle that we can more confidently describe what would be detrimental than what would be beneficial, given the context-dependency of beneficial vegetation traits ${ }^{77}$. Furthermore, it is supported by the notion that ensuring no significant deterioration in air quality is a necessary antecedent in effective species selection for improved air quality ${ }^{105}$. The selection process (Fig. 1) therefore involves four fundamental questions in the following order:

(1) Will the species thrive under the given environmental conditions?

(2) Do the known ecophysiological and morphological characteristics of the species complement the conditions of the urban context (street canyon or open road)?

(3) Will the species contribute minimal emissions?

(4) Does the species bear traits that are deemed to be beneficial for pollution abatement?

This process is intended to ensure that all significant factors are considered before a plant is selected, in accordance with the principle that functional Gl may be achieved only through targeted design based upon local assessments ${ }^{150}$. Taxus baccata, for example, may be beneficial if not planted where de-icing salt spray is known to be prevalent, and if female cultivars are selected for sites near vulnerable populations (Tables 3 and 4). Similarly, Quercus suber may be unsuitable for large-scale planting schemes due to its high bVOC emissions, despite its suite of beneficial leaf characteristics; Sorbus intermedia may be a notable alternative, and observation of the $5-10 \%$ diversity principle should ensure that a number of evergreen species are also identified, which may, if planted alongside Sorbus intermedia, provide the longevity in pollution abatement that Quercus suber may have otherwise offered (Table 3 ). The $5-10 \%$ species diversity principle reflects substantial research indicating that no individual species should comprise more than $5-10 \%$ of a population, which is most effectively observed at city scale ${ }^{146}$.

\section{CONCLUSIONS}

Interactions between $\mathrm{Gl}$ and air quality are part of a complex socioecological system, which makes the isolation and manipulation of functions for a specific objective (i.e. improved pollution mitigation) highly problematic. However, if the spatial scale of the intervention, the context and conditions of the planting site, and the target air pollutant type are taken into account, the selection of plants that exhibit certain biophysical traits can optimise the dispersive and depositional effects of a roadside vegetation barrier (Fig. 2). The initial investigation discussed under 'Coordinated reccomendations for enhanced vegetation barrier design', understood in relation to recommendations made in earlier sections on 'Interactions between GI and air quality', 'Trade-offs in plant selection' and 'Sustainability and species suitability', may be used by practitioners as a starting point for appropriate plant selection when designing vegetation barriers (particularly in open-road environments) for improved urban air quality. Significant findings and recommendations include:

- $\mathrm{Gl}$ can be utilised to reduce pollution exposure at the local scale, but active control (reduced emissions) is the most effective strategy across scales.

- City-scale analyses of interactions between GI and air quality may generate inappropriate planting recommendations, with limitations in down-scaling due to extreme heterogeneity in local-scale conditions and inherent context-dependency in the influences of different forms of $\mathrm{Gl}$ on ambient air quality.

- For street canyons, the aspect ratio is critical to the appropriate $\mathrm{Gl}$ form ${ }^{151}$. In deep street canyons $(H / W \geq 2)$, only green walls are recommended; in mid-depth street canyons (H/W 0.5-2), low-level vegetation (shrubs and low hedges) may also be implemented; and in shallow street canyons (H/W $\leq 0.5$ ), small and open-crowned trees may be additionally planted on the windward side of the canyon, spaced broadly apart (Table 2).

- In open-road environments, vegetation barriers should be implemented at the immediate roadside, with a minimum height of $\sim 2 \mathrm{~m}$ and greater height required with greater distance from the road, in order to screen the pollutant flux ${ }^{20,29,152}$. Where space permits, combinations of low- and high-level vegetation (e.g. a row of trees above a contiguous hedge) should be implemented ${ }^{32,152}$. Leaf coverage should begin at ground level and extend across the entirety of the barrier $^{29,151}$. LAD $>3$ and $<5$ is recommended, although density should be greater where the planting site is narrower, ensuring low porosity, or above average barrier density ${ }^{152}$. 


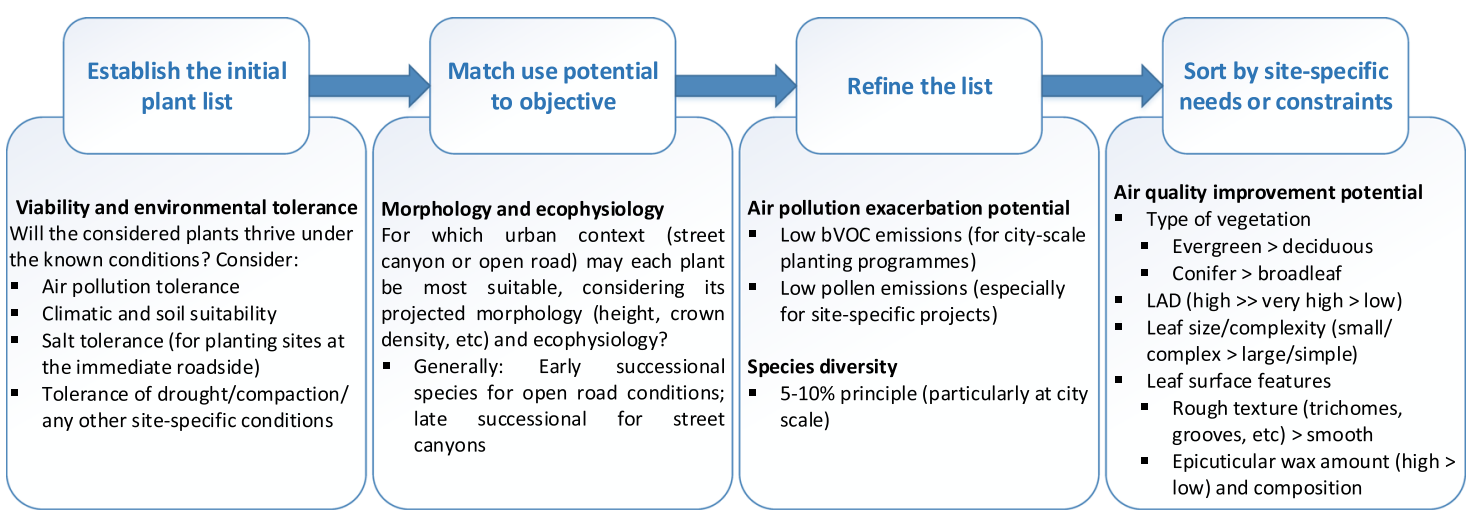

Fig. 1 Schematic representation of a plant species selection process for improved air quality, with a focus on vegetation barriers and particulate pollution. $b V O C$ biogenic volatile organic compound, $L A D$ leaf area density.

Cost-benefit weighting can be altered by barrier design...

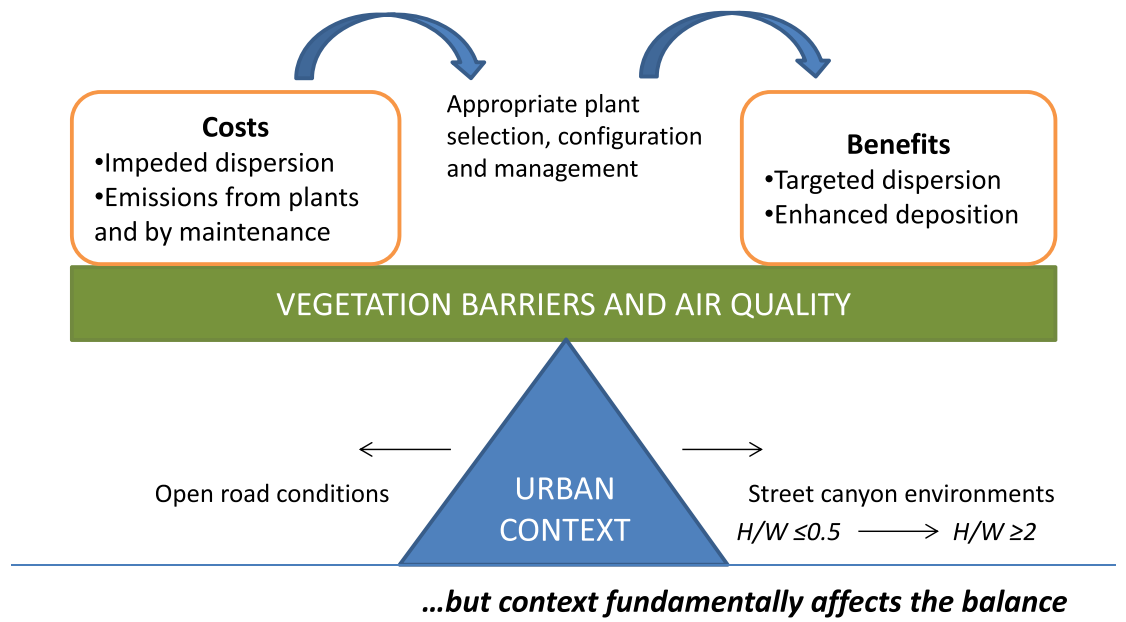

Fig. 2 A graphical overview of vegetation barrier design for air pollution abatement. $H / W$ street canyon height $(H)$ to width $(W)$ ratio.

- Potentially detrimental aspects of GI for ambient air quality include not only the propensity of inappropriate GI forms to inhibit dispersion but the tendency of certain plants to emit high amounts of bVOCs and/or pollen. bVOC emissions are of primary concern for large-scale planting schemes, whereas pollen emissions should be considered on a site-by-site basis.

- Foliage longevity corresponds not only with annual longevity of $\mathrm{Gl}$ performance, but with longevity of any potentially detrimental aspects and susceptibility to environmental stresses, such as air pollution and salt.

- Small, stiff and complex leaves tend to be more effective than larger, less rigid and less complex leaves.

- Beneficial leaf surface features include high stomatal density or size, high epicuticular wax content (particularly for needlelike leaves) and features that increase leaf roughness (e.g. hairs, ridges or grooves), although the comparative significance of different leaf surface features and for different pollutants is not yet clear.

- The implementation of resilient and effective Gl requires careful consideration of the suitability of each plant to each site, including tolerance of relevant stressors and projected growth form.

This review examined the literature on GI and urban air quality, with a focus on species-specific studies, and collated findings to date in order to identify recommendations and important considerations for effective vegetation barrier design. A plant selection system was thereby formulated, and an initial investigation into viable species for UK urban sites was undertaken (Tables 3 and 4). Building upon this investigation is highly recommended, with plant diversity integral to urban ecosystem resilience. A number of other areas for future research were also identified, including: the influences of air pollution on pollen dispersion and allergenicity associated with different plant species; the influences of individual plants and plant traits (e.g. coniferous leaf shapes) on air pollution, and particularly on sub-micrometre PM and gaseous pollutants; the comparative significance of different leaf micromorphological traits for pollutant deposition; and a systems perspective on the interconnections between aspects of $\mathrm{Gl}$, air quality and different urban environmental conditions.

Received: 27 August 2019; Accepted: 2 March 2020; Published online: 26 March 2020

\section{REFERENCES}

1. World Health Organisation. Ambient Air Pollution: A Global Assessment of Exposure and Burden of Disease (World Health Organisation, 2016).

2. Mukherjee, A. \& Agrawal, M. World air particulate matter: sources, distribution and health effects. Environ. Chem. Lett. 15, 283-309 (2017).

3. Kumar, P. et al. New directions: air pollution challenges for developing megacities like Delhi. Atmos. Environ. 122, 657-661 (2015).

4. Kumar, P. et al. New directions: from biofuels to wood stoves: the modern and ancient air quality challenges in the megacity of São Paulo. Atmos. Environ. 140, 364-369 (2016). 
5. United Nations, Department of Economic and Social Affairs, Population Division. World Population Prospects: The 2017 Revision, Key Findings and Advance Tables (United Nations, Department of Economic and Social Affairs, Population Division, 2017).

6. Tibbetts, J. H. Air quality and climate change: a delicate balance. Environ. Health Perspect. 123, 148-153 (2015).

7. Hewitt, C. N., Ashworth, K. \& MacKenzie, A. R. Using green infrastructure to improve urban air quality (GI4AQ). Ambio https://doi.org/10.1007/s13280-01901164-3, 1-12 (2019).

8. Gallagher, J. et al. Passive methods for improving air quality in the built environment: a review of porous and solid barriers. Atmos. Environ. 120, 61-70 (2015).

9. Elmqvist, T. et al. Benefits of restoring ecosystem services in urban areas. Curr. Opin. Environ. Sustain. 14, 101-108 (2015).

10. Kong, F., Yin, H., James, P., Hutyra, L. R. \& He, H. S. Effects of spatial pattern of greenspace on urban cooling in a large metropolitan area of eastern China. Landsc. Urban Plan. 128, 35-47 (2014).

11. Aerts, R., Honnay, O. \& Van Nieuwenhuyse, A. Biodiversity and human health: mechanisms and evidence of the positive health effects of diversity in nature and green spaces. Br. Med. Bull. 127, 5-22 (2018).

12. Beyer, K. et al. Exposure to neighborhood green space and mental health: evidence from the Survey of the Health of Wisconsin. Int. J. Environ. Res. Public Health 11, 3453-3472 (2014).

13. Donovan, G. H. et al. The relationship between trees and human health: evidence from the spread of the emerald ash borer. Am. J. Prev. Med. 44, 139-145 (2013).

14. Hartig, T. \& Kahn, P. H. Jr. Living in cities, naturally. Proc. Natl Acad. Sci. USA 136, 397-409 (2014).

15. Kardan, O. et al. Neighborhood greenspace and health in a large urban center. Sci. Rep. 5, 11610 (2015)

16. Baraldi, R. et al. Ecophysiological and micromorphological characterization of green roof vegetation for urban mitigation. Urban For. Urban Green. 37, 24-32 (2019).

17. Pakzad, P. \& Osmond, P. Developing a sustainability indicator set for measuring green infrastructure performance. Proc. Soc. Behav. Sci. 216, 68-79 (2016).

18. Willis, K. J. \& Petrokofsky, G. The natural capital of city trees. Science $\mathbf{3 5 6}$, 374-376 (2017).

19. Chenoweth, J. et al. The interrelationship of green infrastructure and natural capital. Land Use Policy 75, 137-144 (2018).

20. Abhijith, K. V. et al. Air pollution abatement performances of green infrastructure in open road and built-up street canyon environments-a review. Atmos. Environ. 162, 71-86 (2017).

21. Li, X.-B. et al. The impacts of roadside vegetation barriers on the dispersion of gaseous traffic pollution in urban street canyons. Urban For. Urban Green. 17, 80-91 (2016).

22. Ortolani, C. \& Vitale, M. The importance of local scale for assessing, monitoring and predicting of air quality in urban areas. Sustain. Cities Soc. 26, 150-160 (2016).

23. Kumar, P. et al. Dynamics of coarse and fine particle exposure in transport microenvironments. npj Clim. Atmos. Sci. 1, 11 (2018).

24. Patton, A. P. et al. Spatial and temporal differences in traffic-related air pollution in three urban neighborhoods near an interstate highway. Atmos. Environ. 99, 309-321 (2014)

25. Grigoratos, T. \& Martini, G. Brake wear particle emissions: a review. Environ. Sci. Pollut. Res. 22, 2491-2504 (2015).

26. Kumar, P., Pirjola, L., Ketzel, M. \& Harrison, R. M. Nanoparticle emissions from 11 non-vehicle exhaust sources-a review. Atmos. Environ. 67, 252-277 (2013).

27. Font, A. \& Fuller, G. W. Did policies to abate atmospheric emissions from traffic have a positive effect in London? Environ. Pollut. 218, 463-474 (2016).

28. Sæbø, A., Janhäll, S., Gawronski, S. W. \& Hanslin, H. M. in Routledge Handbook of Urban Forestry (eds Ferrini, F., Konijnendijk van den Bosch, C. \& Fini, A.) 112-122 (Routledge, 2017).

29. Janhäll, S. Review on urban vegetation and particle air pollution-deposition and dispersion. Atmos. Environ. 105, 130-137 (2015).

30. Säumel, I., Weber, F. \& Kowarik, I. Toward livable and healthy urban streets: roadside vegetation provides ecosystem services where people live and move. Environ. Sci. Policy https://doi.org/10.1016/j.envsci.2015.11.012 (2015).

31. Greater London Authority. Using Green Infrastructure to Protect People from Air Pollution (Greater London Authority, 2019).

32. Abhijith, K. V. \& Kumar, P. Field investigations for evaluating green infrastructure effects on air quality in open-road conditions. Atmos. Environ. 201, 132-147 (2019).

33. Al-Dabbous, A. N. \& Kumar, P. The influence of roadside vegetation barriers on airborne nanoparticles and pedestrians exposure under varying wind conditions. Atmos. Environ. 90, 113-124 (2014).

34. Baldauf, R. Roadside vegetation design characteristics that can improve local, near-road air quality. Transp. Res. Part D 52, 354-361 (2017)

35. Tremper, A. H., Green, D. C. \& Eleftheriou-Vaus, K. Impact of Green Screens on Concentrations of Particulate Matter and Oxides of Nitrogen in Near Road Environments (King's College London, London, 2015).
36. Sæbø, A. et al. Plant species differences in particulate matter accumulation on leaf surfaces. Sci. Total Environ. 427-428, 347-354 (2012).

37. Yang, J., Chang, Y. \& Yan, P. Ranking the suitability of common urban tree species for controlling PM2.5 pollution. Atmos. Pollut. Res. 6, 267-277 (2015).

38. Churkina, G., Grote, R., Butler, T. M. \& Lawrence, M. Natural selection? Picking the right trees for urban greening. Environ. Sci. Policy 47, 12-17 (2015).

39. Baraldi, R. et al. An integrated study on air mitigation potential of urban vegetation: from a multi-trait approach to modeling. Urban For. Urban Green. 41 127-138 (2019).

40. Donovan, R. G., Stewart, H. E., Owen, S. M., MacKenzie, A. R. \& Hewitt, C. N. Development and Application of an Urban Tree Air Quality Score for Photochemical Pollution Episodes using the Birmingham, United Kingdom, Area as a Case Study (2005). https://doi.org/10.1021/ES050581Y.

41. Hirons, A. \& Sjöman, H. Tree Species Selection for Green Infrastructure: A Guide for Specifiers (Trees \& Design Action Group, 2018).

42. Air Quality Expert Group. Impacts of Vegetation on Urban Air Pollution (Air Quality Expert Group, 2018).

43. Selmi, W. et al. Air pollution removal by trees in public green spaces in Strasbourg city, France. Urban For. Urban Green. 17, 192-201 (2016).

44. Demuzere, M. et al. Mitigating and adapting to climate change: multi-functional and multi-scale assessment of green urban infrastructure. J. Environ. Manag. 146, 107-115 (2014).

45. Salmond, J. A. et al. Health and climate related ecosystem services provided by street trees in the urban environment. Environ. Health 15, S36 (2016).

46. Irfan, M., Shah, H., Koj, A. \& Thomas, H. Finding space to grow urban hedges as a natural air filter along pedestrian paths: a GIS-based investigation of a UK urban centre. Euro-Mediterranean J. Environ. Integr. 3, 40 (2018).

47. Ferranti, E. J. S., MacKenzie, A. R., Levine, J. G., Ashworth, K. \& Hewitt, C. N. First Steps in Urban Air Quality 2nd edn. A Trees \& Design Action Group (TDAG) Guidance Document (2019).

48. Tiwari, A. et al. Considerations for evaluating green infrastructure impacts in microscale and macroscale air pollution dispersion models. Sci. Total Environ. https://doi.org/10.1016/J.SCITOTENV.2019.03.350 (2019).

49. McNabola, A. New directions: passive control of personal air pollution exposure from traffic emissions in urban street canyons. Atmos. Environ. 44, 2940-2941 (2010).

50. Salmond, J. A. et al. The influence of vegetation on the horizontal and vertical distribution of pollutants in a street canyon. Sci. Total Environ. 443, 287-298 (2013).

51. Morakinyo, T. E. \& Lam, Y. F. Study of traffic-related pollutant removal from street canyon with trees: dispersion and deposition perspective. Environ. Sci. Pollut. Res. 23, 21652-21668 (2016).

52. Buccolieri, R., Jeanjean, A. P. R., Gatto, E. \& Leigh, R. J. The impact of trees on street ventilation, $\mathrm{NO}_{\mathrm{x}}$ and $\mathrm{PM}_{2.5}$ concentrations across heights in Marylebone Rd street canyon, central London. Sustain Cities Soc. 41, 227-241 (2018).

53. Deshmukh, P. et al. The effects of roadside vegetation characteristics on local, near-road air quality. Air Qual. Atmos. Health https://doi.org/10.1007/s11869018-0651-8 (2018).

54. Ghasemian, M., Amini, S. \& Princevac, M. The influence of roadside solid and vegetation barriers on near-road air quality. Atmos. Environ. 170, 108-117 (2017).

55. Tong, Z., Baldauf, R. W., Isakov, V., Deshmukh, P. \& Zhang, M. K. Roadside vegetation barrier designs to mitigate near-road air pollution impacts. Sci. Total Environ. 541, 920-927 (2016).

56. Kumar, P., Ketzel, M., Vardoulakis, S., Pirjola, L. \& Britter, R. Dynamics and dispersion modelling of nanoparticles from road traffic in the urban atmospheric environment-a review. J. Aerosol Sci. 42, 580-603 (2011).

57. Leung, D. Y. C. et al. Effects of urban vegetation on urban air quality. Landsc. Res. 36, 173-188 (2011).

58. Churkina, G. et al. Effect of VOC emissions from vegetation on air quality in Berlin during a heatwave. Environ. Sci. Technol. 51, 6120-6130 (2017).

59. Fitzky, A. C. et al. The interplay between ozone and urban vegetation - bVOC emissions, ozone deposition, and tree ecophysiology. Front. For. Glob. Chang. 2, 1-17 (2019).

60. World Health Organization. Occupational and Environmental Health Team. WHO Air Quality Guidelines for Particulate Matter, Ozone, Nitrogen Dioxide and Sulfur Dioxide: Global Update 2005: Summary of Risk Assessment (WHO, 2006).

61. Heal, M. R., Kumar, P. \& Harrison, R. M. Particles, air quality, policy and health. Chem. Soc. Rev. 41, 6606 (2012).

62. Gohar, L., Bernie, D., Good, P. \& Lowe, J. A. UKCP18 Derived Projections of Future Climate over the UK (Met Office, 2018).

63. Ren, Y. et al. Air quality and health effects of biogenic volatile organic compounds emissions from urban green spaces and the mitigation strategies. Environ. Pollut. 230, 849-861 (2017).

64. Guenther, A. Biological and chemical diversity of biogenic volatile organic emissions into the atmosphere. ISRN Atmos. Sci. 2013, 1-27 (2013). 
65. Benjamin, M. T. \& Winer, A. M. Estimating the ozone-forming potential of urban trees and shrubs. Atmos. Environ. 32, 53-68 (1998).

66. Laothawornkitkul, J., Taylor, J. E., Paul, N. D. \& Hewitt, C. N. Biogenic volatile organic compounds in the Earth system. N. Phytol. 183, 27-51 (2009).

67. Simpson, J. R. \& McPherson, E. G. The tree BVOC index. Environ. Pollut. https:// doi.org/10.1016/j.envpol.2011.02.034 (2011).

68. Sjöman, H., Morgenroth, J., Sjöman, J. D., Sæbø, A. \& Kowarik, I. Diversification of the urban forest-can we afford to exclude exotic tree species? Urban For. Urban Green. 18, 237-241 (2016).

69. Cariñanos, P. \& Casares-Porcel, M. Urban green zones and related pollen allergy: a review. Some guidelines for designing spaces with low allergy impact. Landsc. Urban Plan. 101, 205-214 (2011).

70. Reinmuth-Selzle, K. et al. Air pollution and climate change effects on allergies in the anthropocene: abundance, interaction, and modification of allergens and adjuvants. Environ. Sci. Technol. 51, 4119-4141 (2017).

71. Cuinica, L. G., Abreu, I. \& Esteves da Silva, J. Effect of air pollutant $\mathrm{NO}_{2}$ on Betula pendula, Ostrya carpinifolia and Carpinus betulus pollen fertility and human allergenicity. Environ. Pollut. 186, 50-55 (2014).

72. Cuinica, L. G., Cruz, A., Abreu, I. \& Esteves da Silva, J. C. G. Effects of atmospheric pollutants $\left(\mathrm{CO}, \mathrm{O}_{3}, \mathrm{SO}_{2}\right)$ on the allergenicity of Betula pendula, Ostrya carpinifolia, and Carpinus betulus pollen. Int. J. Environ. Health Res. 25, 312-321 (2014).

73. Sénéchal, $H$. et al. A review of the effects of major atmospheric pollutants on pollen grains, pollen content, and allergenicity. Scientific World J. 2015, 940243 (2015).

74. Ogren, T. L. The Allergy-Fighting Garden: Stop Asthma and Allergies qith Smart Landscaping (Ten Seed Press, 2015).

75. Farré-Armengol, G. et al. Ozone degrades floral scent and reduces pollinator attraction to flowers. N. Phytol. https://doi.org/10.1111/nph.13620 (2016).

76. Pugh, T. A. M., MacKenzie, A. R., Whyatt, J. D. \& Hewitt, C. N. Effectiveness of green infrastructure for improvement of air quality in urban street canyons. Environ. Sci. Technol. https://doi.org/10.1021/es300826w (2012).

77. Grote, R. et al. Functional traits of urban trees: air pollution mitigation potential. Front. Ecol. Environ. 14, 543-550 (2016).

78. Leonard, R. J., McArthur, C. \& Hochuli, D. F. Particulate matter deposition on roadside plants and the importance of leaf trait combinations. Urban For. Urban Green. 20, 249-253 (2016).

79. Giardina, M. \& Buffa, P. A new approach for modeling dry deposition velocity of particles. Atmos. Environ. 180, 11-22 (2018).

80. Khan, T. R. \& Perlinger, J. A. Evaluation of five dry particle deposition parameterizations for incorporation into atmospheric transport models. Geosci. Model Dev. https://doi.org/10.5194/gmd-10-3861-2017 (2017).

81. Ranasinghe, D. et al. Effectiveness of vegetation and sound wall-vegetation combination barriers on pollution dispersion from freeways under early morning conditions. Sci. Total Environ. 658, 1549-1558 (2019).

82. Jeanjean, A. P. R., Buccolieri, R., Eddy, J., Monks, P. S. \& Leigh, R. J. Air quality affected by trees in real street canyons: the case of Marylebone neighbourhood in central London. Urban For. Urban Green. 22, 41-53 (2017).

83. Santiago, J.-L. et al. CFD modelling of vegetation barrier effects on the reduction of traffic-related pollutant concentration in an avenue of Pamplona, Spain. Sustain. Cities Soc. 48, 101559 (2019).

84. Xing, Y. \& Brimblecombe, P. Role of vegetation in deposition and dispersion of air pollution in urban parks. Atmos. Environ. 201, 73-83 (2019).

85. Xue, F. \& Li, X. The impact of roadside trees on traffic released PM10 in urban street canyon: aerodynamic and deposition effects. Sustain. Cities Soc. https:// doi.org/10.1016/j.scs.2017.02.001 (2017).

86. Morakinyo, T. E. \& Lam, Y. F. Simulation study of dispersion and removal of particulate matter from traffic by road-side vegetation barrier. Environ. Sci. Pollut. Res. 23, 6709-6722 (2016).

87. Buccolieri, R., Santiago, J.-L., Rivas, E. \& Sanchez, B. Review on urban tree modelling in CFD simulations: aerodynamic, deposition and thermal effects. Urban For. Urban Green. 31, 212-220 (2018).

88. Mo, L. et al. Assessing the capacity of plant species to accumulate particulate matter in Beijing, China. PLOS ONE 10, e0140664 (2015).

89. Perini, K., Ottelé, M., Giulini, S., Magliocco, A. \& Roccotiello, E. Quantification of fine dust deposition on different plant species in a vertical greening system. Ecol. Eng. 100, 268-276 (2017).

90. Weerakkody, U., Dover, J. W., Mitchell, P. \& Reiling, K. Particulate matter pollution capture by leaves of seventeen living wall species with special reference to railtraffic at a metropolitan station. Urban For. Urban Green. 27, 173-186 (2017).

91. Weerakkody, U., Dover, J. W., Mitchell, P. \& Reiling, K. Evaluating the impact of individual leaf traits on atmospheric particulate matter accumulation using natural and synthetic leaves. Urban For. Urban Green. 30, 98-107 (2018).

92. Abelleira Martínez, O. J. et al. Scaling up functional traits for ecosystem services with remote sensing: concepts and methods. Ecol. Evol. 6, 4359-4371 (2016).

93. Smith, J. Urban Air Quality (The Woodland Trust, Grantham, 2012).
94. Seyednasrollah, B., Swenson, J. J., Domec, J.-C. \& Clark, J. S. Leaf phenology paradox: Why warming matters most where it is already warm. Remote Sens. Environ. 209, 446-455 (2018).

95. Roupsard, O. et al. Reverse phenology and dry-season water uptake by Faidherbia albida (Del.) A. Chev. in an agroforestry parkland of Sudanese west Africa. Funct. Ecol. 13, 460-472 (1999).

96. Oshio, H., Asawa, T., Hoyano, A. \& Miyasaka, S. Estimation of the leaf area density distribution of individual trees using high-resolution and multi-return airborne LiDAR data. Remote Sens. Environ. 166, 116-125 (2015).

97. Steffens, J. T., Wang, Y. J. \& Zhang, K. M. Exploration of effects of a vegetation barrier on particle size distributions in a near-road environment. Atmos. Environ. 50, 120-128 (2012).

98. Chen, X. et al. Efficiency differences of roadside greenbelts with three configurations in removing coarse particles (PM10): a street scale investigation in Wuhan, China. Urban For. Urban Green. 14, 354-360 (2015).

99. Lee, E. S. et al. Field evaluation of vegetation and noise barriers for mitigation of near-freeway air pollution under variable wind conditions. Atmos. Environ. 175, 92-99 (2018).

100. Santiago, J. L., Rivas, E., Sanchez, B., Buccolieri, R. \& Martin, F. The impact of planting trees on $\mathrm{NO}_{x}$ concentrations: the case of the Plaza de la Cruz neighborhood in Pamplona (Spain). Atmosphere (Basel) 8, 131 (2017).

101. Raupach, M. R., Woods, N., Dorr, G., Leys, J. F. \& Cleugh, H. A. The entrapment of particles by windbreaks. Atmos. Environ. 35, 3373-3383 (2001).

102. Neft, I., Scungio, M., Culver, N. \& Singh, S. Simulations of aerosol filtration by vegetation: validation of existing models with available lab data and application to near-roadway scenario. Aerosol Sci. Technol. 50, 937-946 (2016).

103. Viecco, M. et al. Potential of particle matter dry deposition on green roofs and living walls vegetation for mitigating urban atmospheric pollution in semiarid climates. Sustainability 10, 2431 (2018).

104. Weerakkody, U., Dover, J. W., Mitchell, P. \& Reiling, K. Quantification of the traffic-generated particulate matter capture by plant species in a living wall and evaluation of the important leaf characteristics. Sci. Total Environ. 635, 1012-1024 (2018).

105. Chen, L., Liu, C., Zhang, L., Zou, R. \& Zhang, Z. Variation in tree species ability to capture and retain airborne fine particulate matter (PM2.5). Sci. Rep. 7, 3206 (2017).

106. Tallis, M., Taylor, G., Sinnett, D. \& Freer-Smith, P. Estimating the removal of atmospheric particulate pollution by the urban tree canopy of London, under current and future environments. Landsc. Urban Plan. 103, 129-138 (2011).

107. Huang, C. W., Lin, M. Y., Khlystov, A. \& Katul, G. G. The effects of leaf size and microroughness on the branch-scale collection efficiency of ultrafine particles. J. Geophys. Res. Atmos. 120, 3370-3385 (2015).

108. Conroy, K. M., Kumar, P. \& Hunt, W. F. in Airborne Particles: Origin, Emissions and Health Impacts (ed. Kumar, P.) (Nova Science Publishers, 2017).

109. Urban, J., Ingwers, M., McGuire, M. A. \& Teskey, R. O. Stomatal conductance increases with rising temperature. Plant Signal. Behav. 12, e1356534 (2017).

110. Song, Y. et al. Particulate matter deposited on leaf of five evergreen species in Beijing, China: source identification and size distribution. Atmos. Environ. 105, 53-60 (2015).

111. Zhang, W., Wang, B. \& Niu, X. Relationship between leaf surface characteristics and particle capturing capacities of different tree species in Beijing. Forests 8, 92 (2017).

112. Zhang, W., Zhang, Z., Meng, H. \& Zhang, T. How does leaf surface micromorphology of different trees impact their ability to capture particulate matter? Forests 9, 681 (2018).

113. Wang, L., Gong, H., Liao, W. \& Wang, Z. Accumulation of particles on the surface of leaves during leaf expansion. Sci. Total Environ. 532, 420-434 (2015).

114. Burkhardt, J. Hygroscopic particles on leaves: nutrients or desiccants? Ecol. Monogr. 80, 369-399 (2010).

115. Liang, D., Ma, C., Wang, Y. Q., Wang, Y. J. \& Chen-xi, Z. Quantifying PM2.5 capture capability of greening trees based on leaf factors analyzing. Environ. Sci. Pollut. Res. 23, 21176-21186 (2016).

116. Lawson, T. \& Blatt, M. R. Stomatal size, speed, and responsiveness impact on photosynthesis and water use efficiency. Plant Physiol. 164, 1556-1570 (2014).

117. Chen, J., Yu, X., Bi, H. \& Fu, Y. Indoor simulations reveal dixerences among plant species in capturing particulate matter. PLoS ONE 12, e0177539 (2017).

118. Muhammad, S., Wuyts, K. \& Samson, R. Atmospheric net particle accumulation on 96 plant species with contrasting morphological and anatomical leaf characteristics in a common garden experiment. Atmos. Environ. 202, 328-344 (2019).

119. Zhang, L., Routsong, R. \& Strand, S. E. Greatly enhanced removal of volatile organic carcinogens by a genetically modified houseplant, pothos ivy (Epipremnum aureum) expressing the mammalian cytochrome P450 2e1 gene. Environ. Sci. Technol. 53, 325-331 (2019).

120. Tiwary, A. et al. Development of multi-functional streetscape green infrastructure using a performance index approach. Environ. Pollut. 208, 209-220 (2016). 
121. Hilbert, D., Roman, L., Koeser, A. K. \& Vogt, J. Urban tree mortality: a literature review. Arboric. Urban 45, 167-200 (2019).

122. Forestry Commission England. Urban Tree Manual (Forestry Commission England, 2018).

123. Roman, L. A., Battles, J. J. \& McBride, J. R. Determinants of establishment survival for residential trees in Sacramento County, CA. Landsc. Urban Plan. 129, 22-31 (2014).

124. Mullaney, J., Lucke, T. \& Trueman, S. J. A review of benefits and challenges in growing street trees in paved urban environments. Landsc. Urban Plan. https:// doi.org/10.1016/j.landurbplan.2014.10.013 (2015).

125. Jankovska, I. et al. Tree species establishment in urban forest in relation to vegetation composition, tree canopy gap area and soil factors. Forests 6, 4451-4461 (2015)

126. Roman, L. A. et al. Stewardship matters: case studies in establishment success of urban trees. Urban For. Urban Green. 14, 1174-1182 (2015).

127. Sherman, A. R., Kane, B., Autio, W. A., Harris, J. R. \& Ryan, H. D. P. Establishment period of street trees growing in the Boston, MA metropolitan area. Urban For. Urban Green. 19, 95-102 (2016).

128. Conway, T. M., Almas, A. D. \& Coore, D. Ecosystem services, ecological integrity, and native species planting: How to balance these ideas in urban forest management? Urban For. Urban Green. 41, 1-5 (2019).

129. Sade, N., Gebremedhin, A. \& Moshelion, M. Risk-taking plants: anisohydric behavior as a stress-resistance trait. Plant Signal. Behav. 7, 767-770 (2012).

130. Sjöman, H., Hirons, A. D. \& Bassuk, N. L. Improving confidence in tree species selection for challenging urban sites: a role for leaf turgor loss. Urban Ecosyst. 21, 1171-1188 (2018).

131. Burkhardt, J. \& Pariyar, S. Particulate pollutants are capable to 'degrade' epicuticular waxes and to decrease the drought tolerance of Scots pine (Pinus sylvestris L.). Environ. Pollut. 184, 659-667 (2014).

132. Gourdji, S. Review of plants to mitigate particulate matter, ozone as well as nitrogen dioxide air pollutants and applicable recommendations for green roofs in Montreal, Quebec. Environ. Pollut. https://doi.org/10.1016/j.envpol.2018.05.053 (2018).

133. Appleton, B. et al. Air pollution. Virginia Cooperative Extension, Virginia Tech, Virginia State University Publication number 430-022, 1-3 (2014)

134. Rai, P. K. Impacts of particulate matter pollution on plants: Implications for environmental biomonitoring. Ecotoxicol. Environ. Saf. https://doi.org/10.1016/j. ecoenv.2016.03.012 (2016)

135. Achakzai, K. et al. Air pollution tolerance index of plants around brick kilns in Rawalpindi, Pakistan. J. Environ. Manag. 190, 252-258 (2017).

136. Bharti, S. K., Trivedi, A. \& Kumar, N. Air pollution tolerance index of plants growing near an industrial site. Urban Clim. 24, 820-829 (2018).

137. Krishnaveni, M., Chandrasekar, R., Amsavalli, L., Madhiyan, P. \& Durairaj, S. Air pollution tolerance index of plants at Perumalmalai hills, Salem, Tamil Nadu, India. Int. J. Pharm. Sci. Rev. Res. https://doi.org/10.1200/JCO.2008.17.1850 (2013).

138. Lalitha, J., Dhanam, S. \& Ganesh, K. S. Air Pollution Tolerance Index of certain plants around SIPCOT Industrial Area Cuddalore, Tamil Nadu, India. Int. J. Innov. Res. Sci. Eng. Technol 5, 149-155 (2013).

139. Nadgórska-Socha, A., Kandziora-Ciupa, M., Trzęsicki, M. \& Barczyk, G. Air pollution tolerance index and heavy metal bioaccumulation in selected plant species from urban biotopes. Chemosphere 183, 471-482 (2017).

140. Pandey, A. K., Pandey, M., Mishra, A., Tiwary, S. M. \& Tripathi, B. D. Air pollution tolerance index and anticipated performance index of some plant species for development of urban forest. Urban For. Urban Green. 14, 866-871 (2015).

141. Pandey, A. K., Pandey, M. \& Tripathi, B. D. Air Pollution Tolerance Index of climber plant species to develop Vertical Greenery Systems in a polluted tropical city. Landsc. Urban Plan 144, 119-127 (2015).

142. Pandey, A. K., Pandey, M. \& Tripathi, B. D. Assessment of Air Pollution Tolerance Index of some plants to develop vertical gardens near street canyons of a polluted tropical city. Ecotoxicol. Environ. Saf. 134, 358-364 (2016).

143. Zhang, P. Q. et al. Pollution resistance assessment of existing landscape plants on Beijing streets based on air pollution tolerance index method. Ecotoxicol. Environ. Saf. https://doi.org/10.1016/j.ecoenv.2016.06.003 (2016).

144. Zouari, M. et al. A comparative study of Air Pollution Tolerance Index (APTI) of some fruit plant species growing in the industrial area of Sfax, Tunisia. Pollution 4, 439-446 (2018)

145. Singh, S. K. \& Rao, D. N. Evaluation of the plants for their tolerance to air pollution. In Proc. Symposium on Air Pollution Control, IIT Delhi, November 218-224 (1983).

146. Trees \& Design Action Group. Trees in Hard Landscapes A Guide for Delivery (Trees \& Design Action Group, 2014).

147. Gilman, E. F. \& Watson, D. G. 680 Tree Fact Sheets: Trees by Scientific Name (Environmental Horticulture Department, College of Agricultural and Life Sciences, UF/IFAS, 1993. https://hort.ifas.ufl.edu/database/trees/trees_scientific. shtml. Accessed 15 May 2019.
148. Vieira, J. et al. Green spaces are not all the same for the provision of air purification and climate regulation services: the case of urban parks. Environ. Res. 160, 306-313 (2018).

149. Tomaszewski, D. \& Zieliński, J. Epicuticular wax structures on stems and comparison between stems and leaves-a survey. Flora 209, 215-232 (2014).

150. Madureira, H. \& Andresen, T. Planning for multifunctional urban green infrastructures: promises and challenges. URBAN Des. Int. 19, 38-49 (2014).

151. Kumar, P., Abhijith, K. V. \& Barwise, Y. Implementing Green Infrastructure for Air Pollution Abatement: General Recommendations for Management and Plant Species Selection (2019). https://doi.org/10.6084/m9.figshare.8198261.v1.

152. Mori, J. et al. Air pollution deposition on a roadside vegetation barrier in a Mediterranean environment: combined effect of evergreen shrub species and planting density. Sci. Total Environ. 643, 725-737 (2018).

153. Eisenman, T. S. et al. Urban trees, air quality, and asthma: an interdisciplinary review. Landsc. Urban Plan 187, 47-59 (2019).

154. Mori, J., Ferrini, F. \& Saebo, A. Air pollution mitigation by urban greening. Italus Hortus 25, 13-22 (2018).

155. Calfapietra, C. et al. Role of biogenic volatile organic compounds (BVOC) emitted by urban trees on ozone concentration in cities: a review. Environ. Pollut. 183, 71-80 (2013).

\section{ACKNOWLEDGEMENTS}

We are grateful for support received from the EPSRC-funded INHALE (Health assessment across biological length scales for personal pollution exposure and its mitigation; EP/T003189/1) project, the iSCAPE (Improving the Smart Control of Air Pollution in Europe) project, which is funded by the European Community's H2020 Programme (H2020-SC5-04-2015) under Grant Agreement No. 689954, and the University of Surrey's Urban Living Award (2019) for the HedgeDATE (Hedge Design for the Abatement of Traffic Emissions) project. We also thank the University of Surrey and its Department of Civil and Environmental Engineering for an EPSRC Ph.D. studentship (2018-2021), awarded through the University Research Scholarship scheme, to support Y.B.'s Ph.D. research.

\section{AUTHOR CONTRIBUTIONS}

P.K. proposed the concept and supervised. Y.B. created the first draft of the article. The authors contributed equally in revising and finalising the manuscript.

\section{COMPETING INTERESTS}

The authors declare no competing interests.

\section{ADDITIONAL INFORMATION}

Supplementary information is available for this paper at https://doi.org/10.1038/ s41612-020-0115-3.

Correspondence and requests for materials should be addressed to P.K.

Reprints and permission information is available at http://www.nature.com/ reprints

Publisher's note Springer Nature remains neutral with regard to jurisdictional claims in published maps and institutional affiliations.

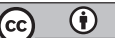

Open Access This article is licensed under a Creative Commons Attribution 4.0 International License, which permits use, sharing, adaptation, distribution and reproduction in any medium or format, as long as you give appropriate credit to the original author(s) and the source, provide a link to the Creative Commons license, and indicate if changes were made. The images or other third party material in this article are included in the article's Creative Commons license, unless indicated otherwise in a credit line to the material. If material is not included in the article's Creative Commons license and your intended use is not permitted by statutory regulation or exceeds the permitted use, you will need to obtain permission directly from the copyright holder. To view a copy of this license, visit http://creativecommons. org/licenses/by/4.0/.

(c) The Author(s) 2020 